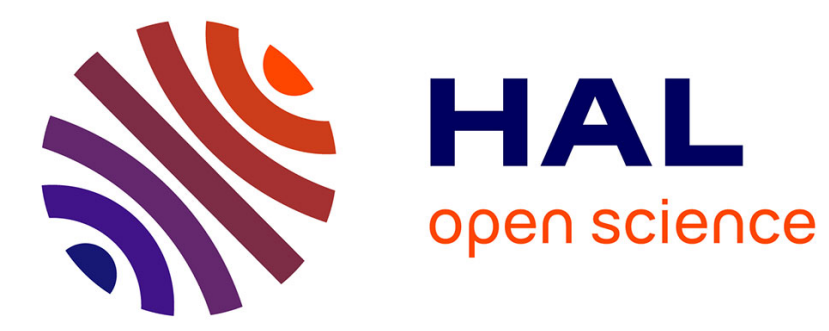

\title{
DEL-sequents for Regression and Epistemic Planning
}

Guillaume Aucher

\section{To cite this version:}

Guillaume Aucher. DEL-sequents for Regression and Epistemic Planning. Journal of Applied NonClassical Logics, 2012, pp.29. hal-00856471

\section{HAL Id: hal-00856471 \\ https://inria.hal.science/hal-00856471}

Submitted on 6 Sep 2015

HAL is a multi-disciplinary open access archive for the deposit and dissemination of scientific research documents, whether they are published or not. The documents may come from teaching and research institutions in France or abroad, or from public or private research centers.
L'archive ouverte pluridisciplinaire HAL, est destinée au dépôt et à la diffusion de documents scientifiques de niveau recherche, publiés ou non, émanant des établissements d'enseignement et de recherche français ou étrangers, des laboratoires publics ou privés. 
Journal of Applied Non-Classical Logics

Vol. 00, No. 00, Month 201X, 1-29

\title{
DEL-sequents for regression and epistemic planning
}

\author{
Guillaume Aucher \\ University of Rennes 1 - INRIA \\ Campus Beaulieu \\ 35042 Rennes Cedex \\ France \\ guillaume.aucher@irisa.fr
}

(August 2011)

\begin{abstract}
Dynamic Epistemic Logic (DEL) deals with the representation and the study in a multiagent setting of knowledge and belief change. It can express in a uniform way epistemic statements about:

(i) what is true about an initial situation

(ii) what is true about an event occurring in this situation

(iii) what is true about the resulting situation after the event has occurred.
\end{abstract}

We axiomatize within the DEL framework what we can infer about (ii) given (i) and (iii) and what we can infer about (i) given (ii) and (iii). Given three formulas $\phi, \phi^{\prime}$ and $\phi^{\prime \prime}$ describing respectively (i), (ii) and (iii), we also show how to build two formulas $\phi \otimes \phi^{\prime \prime}$ and $\phi^{\prime} \oslash \phi^{\prime \prime}$ which capture respectively all the information which can be inferred about (ii) from $\phi$ and $\phi^{\prime \prime}$, and all the information which can be inferred about (i) from $\phi^{\prime}$ and $\phi^{\prime \prime}$. We show how our results extend to other modal logics than K. Finally, we generalize the classical language of dynamic epistemic logic, where one can reason only with complete specifications of events, in order to account also for incomplete description of events. In the companion paper (Aucher, 2011), we axiomatize what we can infer about (iii) given (i) and (ii), and show how to build a formula $\phi \otimes \phi^{\prime}$ which captures all the information which can be inferred about (iii) from $\phi$ and $\phi^{\prime}$.

Keywords: Dynamic epistemic logic, Belief change, Regression, Epistemic planning, Sequent calculus

\section{Introduction}

Dynamic Epistemic Logic (DEL) deals with the representation and the study in a multiagent setting of knowledge and belief change, and more generally of information change (van Ditmarsch, van der Hoek, \& Kooi, 2007). The core idea of DEL is to split the task of representing the agents' beliefs into three parts: first, one represents their beliefs about an initial situation; second, one represents their beliefs about an event taking place in this situation; third, one represents the way the agents update their beliefs about the situation after (or during) the occurrence of the event. Consequently, within the logical framework of DEL, one can express uniformly epistemic statements about:

(i) what is true about an initial situation,

(ii) what is true about an event occurring in this situation,

(iii) what is true about the resulting situation after the event has occurred.

From a logical point of view, this trichotomy begs the following three questions. In these questions, $\phi, \phi^{\prime}$ and $\phi^{\prime \prime}$ are epistemic formulas describing respectively (i), (ii) and (iii). 


\section{Question 1:}

a) Given (i) and (ii), what can we infer about (iii): $\phi, \phi^{\prime} \models \phi^{\prime \prime}$ ?

b) How can we build a single formula $\phi \otimes \phi^{\prime}$ which captures all the information which can be inferred about (iii) from $\phi$ and $\phi^{\prime}$ ?

\section{Question 2:}

a) Given (i) and (iii), what can we infer about (ii): $\phi, \phi^{\prime \prime} \models \phi^{\prime}$ ?

b) How can we build a single formula $\phi \otimes \phi^{\prime \prime}$ which captures all the information which can be inferred about (ii) from $\phi$ and $\phi^{\prime \prime}$ ?

\section{Question 3:}

a) Given (ii) and (iii), what can we infer about (i): $\phi^{\prime}, \phi^{\prime \prime} \models \phi$ ?

b) How can we build a single formula $\phi^{\prime} \oslash \phi^{\prime \prime}$ which captures all the information which can be inferred about (i) from $\phi^{\prime}$ and $\phi^{\prime \prime}$ ?

These three inference problems are related to classical problems addressed under different guises in artificial intelligence and theoretical computer science, which we call respectively progression, epistemic planning and regression. We will not repeat here the conceptual motivations for addressing such questions and how they have been addressed in other logical formalisms since we already spelled it out in the companion paper (Aucher, 2011). In this companion paper, we dealt with the first question. In this paper, we are going to deal with the second and third question. In two other related papers (Aucher, Maubert, \& Schwarzentruber, 2011, 2012), we provided a tableau method (implemented in LOTRECscheme) to decide whether an inference of one of the three kinds above holds and showed that this decision problem is NEXPTIME-complete.

The paper is organized as follows. Sections 2 and 3 are identical to the first two sections of the companion paper (Aucher, 2011) (without the running example and without the Kit Fine formulas for $\mathrm{K}^{\mathrm{P}^{\prime}}$ ). We repeat them in order to make the paper self-contained. In Section 2, we introduce our logical formalism and show how one can naturally express epistemic statements about (i), (ii) and (iii) within this framework. In Section 3, we introduce some mathematical objects needed in the subsequent proofs, namely Kit Fine formulas. Sections 4 and 5 are organized similarly. In both sections, we first provide two equivalent sequent calculi which axiomatize the inference relations of Question 2) a) and of Question 3)a), both for epistemic and ontic events. Then we show how our results extend to other modal logics than K. Afterwards, we define constructively and non-constructively the epistemic planning $\phi \otimes \phi^{\prime \prime}$ from $\phi$ to $\phi^{\prime \prime}$ and the regression $\phi^{\prime} \oslash \phi^{\prime \prime}$ of $\phi^{\prime \prime}$ by $\phi^{\prime}$. Finally, in both sections, we provide an example of epistemic planning and regression. In Section 6, we show how the full BMS language introduced by Baltag, $M$ oss and Solecki can be generalized to account for incomplete descriptions of events. In Section 7, we review the related work and we end the paper with some concluding remarks.

\section{Dynamic Epistemic Logic}

Following the DEL methodology described above, we split the exposition of our logical formalism into three subsections. In the rest of the paper, Agt is a finite set of agents and $\Phi$ is a set of propositional letters called atomic facts. This section is basically the same as Section 2 of (Aucher, 2011) (without the running example and without Remark $9)$. 


\subsection{Representation of the initial situation: $\mathcal{L}$-model}

A (pointed) $\mathcal{L}$-model $(M, w)$ represents how the actual world represented by $w$ is perceived by the agents. Atomic facts are used to state properties of this actual world.

Definition 1 ( $\mathcal{L}$-model). A $\mathcal{L}$-model is a tuple $M=(W, R, V)$ where $W$ is a non-empty set of possible worlds, $R: A g t \rightarrow 2^{W \times W}$ is a function assigning to each agent $j \in$ Agt a relation over $W$ called an accessibility relation, and $V: \Phi \rightarrow 2^{W}$ is a function called a valuation assigning to each propositional letter of $\Phi$ a subset of $W$.

We write $w \in M$ for $w \in W$, and $(M, w)$ is called a pointed $\mathcal{L}$-model. If $w, v \in W$, we write $w R_{j} v$ for $R(j)(w, v)$ and $R_{j}(w)=\left\{v \in W \mid w R_{j} v\right\}$.

Intuitively, in the definition above, $v \in R_{j}(w)$ means that in world $w$ agent $j$ considers world $v$ as being possibly the world $w$.

Now, we define the epistemic language $\mathcal{L}$ which can be used to describe and state properties of $\mathcal{L}$-models. In particular, the formula $B_{j} \phi$ reads as "agent $j$ Believes $\phi$ ". Its truth conditions are defined in such a way that $B_{j} \phi$ holds in a possible world when $\phi$ holds in all the worlds agent $j$ considers possible. Dually, the formula $\left\langle B_{j}\right\rangle \phi$ reads as "agent $j$ considers possible that $\phi$ holds".

Definition 2 (Language $\mathcal{L}$ ). We define the language $\mathcal{L}$ inductively as follows:

$$
\mathcal{L}: \phi \quad:=p \quad|\neg \phi \quad| \phi \wedge \phi \mid B_{j} \phi
$$

where $p$ ranges over $\Phi$ and $j$ over Agt. The formula $\phi \vee \psi$ is an abbreviation for $\neg(\neg \phi \wedge \neg \psi)$, the formula $\phi \rightarrow \psi$ an abbreviation for $\neg \phi \vee \psi$, and the formula $\left\langle B_{j}\right\rangle \phi$ an abbreviation for $\neg B_{j} \neg \phi{ }^{1}$

Let $M$ be a $\mathcal{L}$-model, $w \in M$ and $\phi \in \mathcal{L}$. The satisfaction relation $M, w \models \phi$ is defined inductively as follows:

$$
\begin{array}{lll}
M, w=p & \text { iff } & w \in V(p) \\
M, w \models \neg \phi & \text { iff } & \text { not } M, w=\phi \\
M, w=\phi \wedge \psi & \text { iff } & M, w=\phi \text { and } M, w=\psi \\
M, w=B_{j} \phi & \text { iff } & \text { for all } v \in R_{j}(w), M, v \models \phi
\end{array}
$$

We write $M \mid=\phi$ when $M, w \models \phi$ for all $w \in M$, and $\models \phi$ when $M \models \phi$ for all $\mathcal{L}$-model $M$.

Theorem 1 (Soundness and completeness of K). (Blackburn, de Rijke, \& Venema, 2001) The logic $K$ is defined by the following axiom schemata and inference rules:

$$
\begin{array}{ll}
\text { (Propositional) } & \text { All propositional axiom schemata and inference rules } \\
\text { ( } B_{j} \text {-distribution) } & \vdash B_{j}(\phi \rightarrow \psi) \rightarrow\left(B_{j} \phi \rightarrow B_{j} \psi\right) \\
\text { ( } B_{j} \text {-necessitation) } & \text { If } \vdash \phi \text { then } \vdash B_{j} \phi
\end{array}
$$

A formula $\phi \in \mathcal{L}$ is a $\mathrm{K}$-theorem, written $\phi \in K$, when $\phi$ can be derived by successively applying (some of) the inference rules on (some of) the axioms. $\phi$ is $\mathrm{K}$-inconsistent when $\neg \phi$ is derivable in $K$, and $\mathrm{K}$-consistent otherwise. Then, for all $\phi \in \mathcal{L}, \phi \in K$ implies that $=\phi$ (soundness), and $\models \phi$ implies that $\phi \in K$ (completeness).

\footnotetext{
${ }^{1}$ The degree $\operatorname{deg}(\phi)$ of a formula $\phi \in \mathcal{L}$ is defined inductively as follows: $\operatorname{deg}(p)=0, \operatorname{deg}(\neg \phi)=\operatorname{deg}(\phi), \operatorname{deg}(\phi \wedge \psi)=$ $\max \{\operatorname{deg}(\phi), \operatorname{deg}(\psi)\}, \operatorname{deg}\left(B_{j} \phi\right)=1+\operatorname{deg}(\phi)$. We define similarly the degree $\operatorname{deg}\left(\phi^{\prime}\right)$ of a formula $\phi^{\prime}$ from the language $\mathcal{L}^{\prime}$ of Definition 5 .
} 


\subsection{Representation of the event: $\mathcal{L}^{\prime}$-model}

The propositional letters $p^{\prime}$ describing events are called atomic events and range over an infinite set $\Phi^{\prime}$. To each atomic event $p^{\prime}$, we assign a formula $\operatorname{Pre}\left(p^{\prime}\right)$ of the language $\mathcal{L}$, which is called the precondition of $p^{\prime}$. This precondition corresponds to the property that should be true at any world $w$ of a $\mathcal{L}$-model so that the atomic event $p^{\prime}$ can 'physically' occur in this world $w$.

Definition 3 (Precondition function). A precondition function Pre : $\Phi^{\prime} \rightarrow \mathcal{L}$ is a surjective function which assigns to each propositional letter $p^{\prime}$ a formula of $\mathcal{L}$.

Note that the definition above constrains indirectly the definition of the infinite set $\Phi^{\prime}$. Also, note that if precondition functions were bijective, then all the results of this paper and its companion paper (Aucher, 2011) would still hold.

A pointed $\mathcal{L}^{\prime}$-model $\left(M^{\prime}, w^{\prime}\right)$ represents how the actual event represented by $w^{\prime}$ is perceived by the agents.

Definition 4 ( $\mathcal{L}^{\prime}$-model). A $\mathcal{L}^{\prime}$-model is a tuple $M^{\prime}=\left(W^{\prime}, R^{\prime}, V^{\prime}\right)$ where $W^{\prime}$ is a nonempty set of possible events, $R^{\prime}: A g t \rightarrow 2^{W^{\prime} \times W^{\prime}}$ is a function assigning to each agent $j \in A g t$ a relation over $W$ called an accessibility relation, and $V^{\prime}: \Phi^{\prime} \rightarrow 2^{W^{\prime}}$ is a function called a valuation assigning to each propositional letter of $\Phi^{\prime}$ a subset of $W^{\prime}$ such that

$$
\text { for all } w^{\prime} \in W^{\prime} \text {, there is at most one } p^{\prime} \text { such that } w^{\prime} \in V\left(p^{\prime}\right) \text {. (Exclusivity) }
$$

We write $w^{\prime} \in M^{\prime}$ for $w^{\prime} \in W^{\prime}$, and $\left(M^{\prime}, w^{\prime}\right)$ is called a pointed $\mathcal{L}^{\prime}$-model. If $w^{\prime}, v^{\prime} \in W^{\prime}$, we write $w^{\prime} R_{j}^{\prime} v^{\prime}$ for $R^{\prime}(j)\left(w^{\prime}, v^{\prime}\right)$ and $R_{j}^{\prime}\left(w^{\prime}\right)=\left\{v^{\prime} \in W^{\prime} \mid w^{\prime} R_{j}^{\prime} v^{\prime}\right\}$.

Intuitively, $v^{\prime} \in R_{j}\left(w^{\prime}\right)$ means that while the possible event represented by $w^{\prime}$ is occurring, agent $j$ considers possible that the possible event represented by $v^{\prime}$ is actually occurring. The condition (Exclusivity) expresses in our framework the fact that a single precondition is assigned to each possible event, as in the standard BMS framework of (Baltag \& Moss, 2004). This BMS logical framework will be generalized in Section 6 .

Just as we defined a language $\mathcal{L}$ for epistemic models, we also define a language $\mathcal{L}^{\prime}$ for $\mathcal{L}^{\prime}$-models whose truth conditions are identical to the ones of the language $\mathcal{L}$. This language was already introduced in (Baltag, Moss, \& Solecki, 1999). In the sequel, formulas of $\mathcal{L}^{\prime}$ will always be indexed by the quotation mark', unlike formulas of $\mathcal{L}$.

Definition 5 (Language $\mathcal{L}^{\prime}$ ). We define the language $\mathcal{L}^{\prime}$ inductively as follows:

$$
\mathcal{L}^{\prime}: \phi^{\prime}::=p^{\prime} \quad\left|\neg \phi^{\prime} \quad\right| \phi^{\prime} \wedge \phi^{\prime} \mid B_{j} \phi^{\prime}
$$

where $p^{\prime}$ ranges over $\Phi^{\prime}$ and $j$ over Agt. The formula $\phi^{\prime} \vee \psi^{\prime}$ is an abbreviation for $\neg\left(\neg \phi^{\prime} \wedge \neg \psi^{\prime}\right)$, the formula $\phi^{\prime} \rightarrow \psi^{\prime}$ is an abbreviation for $\neg \phi^{\prime} \vee \psi^{\prime}$, and the formula $\left\langle B_{j}\right\rangle \phi^{\prime}$ is an abbreviation for $\neg B_{j} \neg \phi^{\prime}$.

Let $M^{\prime}$ be a $\mathcal{L}^{\prime}$-model, $w^{\prime} \in M^{\prime}$ and $\phi^{\prime} \in \mathcal{L}^{\prime}$. The satisfaction relation $M^{\prime}, w^{\prime}=\phi^{\prime}$ is defined inductively as follows:

$$
\begin{array}{lll}
M^{\prime}, w^{\prime}=p^{\prime} & \text { iff } & w^{\prime} \in V^{\prime}\left(p^{\prime}\right) \\
M^{\prime}, w^{\prime}=\neg \phi^{\prime} & \text { iff } & \text { not } M^{\prime}, w^{\prime}=\phi^{\prime} \\
M^{\prime}, w^{\prime}=\phi^{\prime} \wedge \psi^{\prime} & \text { iff } & M^{\prime}, w^{\prime} \models \phi^{\prime} \text { and } M^{\prime}, w^{\prime} \models \psi^{\prime} \\
M^{\prime}, w^{\prime}=B_{j} \phi^{\prime} & \text { iff } & \text { for all } v^{\prime} \in R_{j}^{\prime}\left(w^{\prime}\right), M^{\prime}, v^{\prime} \models \phi^{\prime} .
\end{array}
$$

We write $M^{\prime} \models \phi^{\prime}$ when $M^{\prime}, w^{\prime} \models \phi^{\prime}$ for all $w^{\prime} \in M^{\prime}$, and $\models \phi^{\prime}$ when $M^{\prime} \models \phi^{\prime}$ for all $\mathcal{L}^{\prime}$-model $M^{\prime}$. 
Now, we introduce the notion of $P^{\prime}$-complete models which will play a technical role in the axiomatization of our inference relation in the next sections.

Definition 6 ( $P^{\prime}$-complete $\mathcal{L}^{\prime}$-model). Let $P^{\prime}$ be a subset of $\Phi^{\prime}$. A $P^{\prime}$-complete $\mathcal{L}^{\prime}$-model is a $\mathcal{L}^{\prime}$-model $M^{\prime}$ such that

for all $w^{\prime} \in M^{\prime}$, there is a unique $p^{\prime} \in P^{\prime}$ such that $w^{\prime} \in V^{\prime}\left(p^{\prime}\right) . \quad$ ( $P^{\prime}$-complete)

A complete $\mathcal{L}^{\prime}$-model is a $\Phi^{\prime}$-complete $\mathcal{L}^{\prime}$-model $M^{\prime}$.

Theorem 2 (Soundness and completeness of $\mathrm{K}^{\prime}$ and $\mathrm{K}^{\mathrm{P}^{\prime}}$ ). The logic $\mathrm{K}^{\prime}$ is defined by the following axiom schemata and inference rules:

(Propositional) All propositional axiom schemata and inference rules

(B $B_{j}$-distribution) $\quad \vdash^{\prime} B_{j}\left(\phi^{\prime} \rightarrow \psi^{\prime}\right) \rightarrow\left(B_{j} \phi^{\prime} \rightarrow B_{j} \psi^{\prime}\right)$

(B-necessitation) If $\vdash^{\prime} \phi^{\prime}$ then $\vdash^{\prime} B_{j} \phi^{\prime}$

(Exclusivity) $\quad \vdash^{\prime} p^{\prime} \rightarrow \neg q^{\prime} \quad$ for all $p^{\prime} \neq q^{\prime}$

Let $P^{\prime}$ be a finite subset of $\Phi^{\prime}$. The logic $K^{P^{\prime}}$ is defined by adding to the logic $K^{\prime}$ the following axiom:

$$
\left(P^{\prime} \text {-Complete }\right) \quad \vdash^{\prime} \bigvee_{p^{\prime} \in P^{\prime}} p^{\prime}
$$

We say that a formula $\phi^{\prime} \in \mathcal{L}^{\prime}$ is a $\mathrm{K}^{\prime}$-theorem, written $\phi^{\prime} \in K^{\prime}$, when $\phi^{\prime}$ can be derived by successively applying (some of) the inference rules on (some of) the axioms of $K^{\prime}$. We say that $\phi^{\prime}$ is $\mathrm{K}^{\prime}$-inconsistent when $\neg \phi^{\prime}$ is derivable in $\mathrm{K}^{\prime}$, and $\mathrm{K}^{\prime}$-consistent otherwise. Then, for all $\phi^{\prime} \in \mathcal{L}^{\prime}, \phi^{\prime} \in K^{\prime}$ implies that $\models^{\prime} \phi^{\prime}$ (soundness) and $\models^{\prime} \phi^{\prime}$ implies $\phi^{\prime} \in K^{\prime}$ (completeness). Similar definitions and results hold for $K^{P^{\prime}}$.

\subsection{Update of the initial situation by the event: product update}

The precondition function of Definition 3 induces a precondition function for $\mathcal{L}^{\prime}$-models, which assigns to each possible event $w^{\prime}$ of a $\mathcal{L}^{\prime}$-model a formula of $\mathcal{L}$. This formula corresponds to the property that should be true at any world $w$ of a $\mathcal{L}$-model so that the possible event $w^{\prime}$ can 'physically' occur in the world $w$.

Definition 7 (Precondition function of a $\mathcal{L}^{\prime}$-model). Let $M^{\prime}=\left(W^{\prime}, R^{\prime}, V^{\prime}\right)$ be a $\mathcal{L}^{\prime}$ model. The precondition function of $M^{\prime}$ is the function Pre : $W^{\prime} \rightarrow \mathcal{L}$ defined as follows:

$$
\operatorname{Pre}\left(w^{\prime}\right)= \begin{cases}\operatorname{Pre}\left(p^{\prime}\right) & \text { if there is } p^{\prime} \text { such that } M^{\prime}, w^{\prime}=p^{\prime} \\ \top & \text { otherwise. }\end{cases}
$$

where $T$ is any theorem of $\mathrm{K}$.

We then redefine equivalently in our setting the BMS product update of (Batlag, Moss, $\&$ Solecki, 1998). This product update takes as argument a pointed $\mathcal{L}$-model $(M, w)$ and a pointed $\mathcal{L}^{\prime}$-model $\left(M^{\prime}, w^{\prime}\right)$ representing respectively how an initial situation is perceived by the agents and how an event occurring in this situation is perceived by them, and yields a new pointed $\mathcal{L}$-model $(M, w) \otimes\left(M^{\prime}, w^{\prime}\right)$ representing how the new situation is perceived by the agents after the occurrence of the event. 
Definition 8 (Product update). Let $(M, w)=(W, R, V, w)$ be a pointed $\mathcal{L}$-model and $\left(M^{\prime}, w^{\prime}\right)=\left(W^{\prime}, R^{\prime}, V^{\prime}, w^{\prime}\right)$ be a pointed $\mathcal{L}^{\prime}$-model such that $M, w \models \operatorname{Pre}\left(w^{\prime}\right)$. The product update of $(M, w)$ and $\left(M^{\prime}, w^{\prime}\right)$ is the pointed $\mathcal{L}$-model $(M, w) \otimes\left(M^{\prime}, w^{\prime}\right)=$ $\left(W^{\otimes}, R^{\otimes}, V^{\otimes},\left(w, w^{\prime}\right)\right)$ defined as follows:

$$
\begin{aligned}
W^{\otimes} & =\left\{\left(v, v^{\prime}\right) \in W \times W^{\prime} \mid M, v \models \operatorname{Pre}\left(v^{\prime}\right)\right\} \\
R_{j}^{\otimes}\left(v, v^{\prime}\right) & =\left\{\left(u, u^{\prime}\right) \in W^{\otimes} \mid u \in R_{j}(v) \text { and } u^{\prime} \in R_{j}^{\prime}\left(v^{\prime}\right)\right\} \\
V^{\otimes}(p) & =\left\{\left(v, v^{\prime}\right) \in W^{\otimes}|M, v|=p\right\}
\end{aligned}
$$

\section{Mathematical Intermezzo}

To make this paper self-contained, we briefly recall the definitions of Kit Fine's formulas for the logics $\mathrm{K}$ and $\mathrm{K}^{\prime}$. This section is identical to Section 3 of (Aucher, 2011) (except that we removed the Kit Fine formulas for $\mathrm{K}^{\mathrm{P}^{\prime}}$ ).

\subsection{Kit Fine's formulas for $\mathrm{K}$}

A Kit Fine formula $\delta_{n+1}$ provides a complete syntactic representation of a pointed $\mathcal{L}$ model up to modal depth $n+1$. So, intuitively, if we view a Kit Fine formula $\delta_{n+1}$ of $S_{n+1}$ as the syntactic representation up to modal depth $n+1$ of a possible world $w$ where it holds, a formula $\delta_{n}$ of $S_{n}^{j}$ can also be viewed as a syntactic representation up to modal depth $n$ of a possible world accessible by $R_{j}$ from $w$. This justifies our notations in Equation 7.

Definition 9 (Sets $S_{n}$ ). (Moss, 2007) We define inductively the sets $S_{n}$ for $n \in \mathbb{N}$ as follows:

$$
\begin{aligned}
S_{0} & =\left\{\bigwedge_{p \in S_{0}} p \wedge \bigwedge_{p \notin S_{0}} \neg p \mid S_{0} \subseteq \Phi\right\} \\
S_{n+1} & =\left\{\delta_{0} \wedge \bigwedge_{j \in A g t}\left(\bigwedge_{\delta_{n} \in S_{n}^{j}}\left\langle B_{j}\right\rangle \delta_{n} \wedge B_{j}\left(\bigvee_{\delta_{n} \in S_{n}^{j}} \delta_{n}\right)\right) \mid \delta_{0} \in S_{0}, S_{n}^{j} \subseteq S_{n}\right\} .
\end{aligned}
$$

A formula of $\delta \in S_{n}$ for some $n>0$ will often be written as follows:

$$
\delta=\delta_{0} \wedge \bigwedge_{j \in A g t}\left(\bigwedge_{\gamma \in R_{j}(\delta)}\left\langle B_{j}\right\rangle \gamma \wedge B_{j}\left(\bigvee_{\gamma \in R_{j}(\delta)} \gamma\right)\right)
$$

The following proposition not only tells us that a formula $\delta_{n}$ completely characterizes the structure up to modal depth $n$ of any pointed epistemic model where it holds (first item), but also that the structure of any epistemic model up to modal depth $n$ can be characterized by such a formula $\delta_{n}$ (second item). If $(M, w)$ is a pointed $\mathcal{L}$-model, then $\delta_{n}(M, w)$ will denote the unique element of $S_{n}$ such that $M, w \models \delta_{n}(M, w)$.

Proposition 1. (Moss, 2007) Let $n \in \mathbb{N}$ and $\phi \in \mathcal{L}$ be such that deg $(\phi) \leq n$. 
(1) For all $\delta_{n} \in S_{n}$, either $\delta_{n} \rightarrow \phi \in K$ or $\delta_{n} \rightarrow \neg \phi \in K$.

(2) $\bigvee_{\delta_{n} \in S_{n}} \delta_{n} \in K$.

The following corollary will play an important role in the sequel. It states that any formula (of degree $n$ ) can be reduced to a disjunction of $\delta_{n} \mathrm{~s}$. This explains why these formulas are called normal form formulas. The decomposition of a formula $\phi$ into $\delta$ s somehow captures completely and syntactically the relevant structure of the set of pointed $\mathcal{L}$-models which make $\phi$ true: each $\delta$ can be seen as a syntactic description of the modal structure (up to depth $n$ and modulo bisimulation) of a pointed $\mathcal{L}$-model which makes $\phi$ true.

Corollary 1. Let $n \in \mathbb{N}$ and let $\phi \in \mathcal{L}$ be such that deg $(\phi) \leq n$. Then, there is $S \subseteq S_{n}$ (possibly empty) such that $\phi \leftrightarrow \bigvee_{\delta \in S} \delta \in K$.

\subsection{Kit Fine's formulas for $\mathrm{K}^{\prime}$}

In this section, we adapt the definitions and propositions of the previous section for the logic $\mathrm{K}^{\prime}$. We also define the notion of precondition of a Kit Fine formula for $\mathrm{K}^{\prime}$.

Definition 10 (Sets $S_{n}^{P^{\prime}}$ ). Let $P^{\prime}$ be a finite subset of $\Phi^{\prime}$. We define inductively the sets $S_{n}^{P^{\prime}}$ for $n \in \mathbb{N}$ as follows:

$$
\begin{aligned}
S_{0}^{P^{\prime}} & =P^{\prime} \cup\left\{\bigwedge_{p^{\prime} \in P^{\prime}} \neg p^{\prime}\right\} \\
S_{n+1}^{P^{\prime}} & =\left\{\delta_{0}^{\prime} \wedge \bigwedge_{j \in A g t}\left(\bigwedge_{\delta_{n}^{\prime} \in S_{n}^{j}}\left\langle B_{j}\right\rangle \delta_{n}^{\prime} \wedge B_{j}\left(\bigvee_{\delta_{n}^{\prime} \in S_{n}^{j}} \delta_{n}^{\prime}\right)\right) \mid \delta_{0}^{\prime} \in S_{0}^{P^{\prime}}, S_{n}^{j} \subseteq S_{n}^{P^{\prime}}\right\} .
\end{aligned}
$$

We define the precondition of $\delta^{\prime}$, written $\operatorname{Pre}\left(\delta^{\prime}\right)$, as follows:

$$
\operatorname{Pre}\left(\delta^{\prime}\right)= \begin{cases}\operatorname{Pre}\left(p^{\prime}\right) & \text { if } \delta_{0}^{\prime}=p^{\prime} \\ \top & \text { otherwise }\end{cases}
$$

Proposition 2. Let $n \in \mathbb{N}$ and let $P^{\prime}$ be a finite subset of $\Phi^{\prime}$. Let $\phi^{\prime} \in \mathcal{L}^{\prime}$ be such that $\operatorname{deg}\left(\phi^{\prime}\right) \leq n$ and such that the set of propositional letters appearing in $\phi^{\prime}$ is a subset of $P^{\prime}$.

(1) For all $\delta_{n}^{\prime} \in S_{n}^{P^{\prime}}$, either $\delta_{n}^{\prime} \rightarrow \phi^{\prime} \in K^{\prime}$ or $\delta_{n}^{\prime} \rightarrow \neg \phi^{\prime} \in K^{\prime}$.

(2) $\bigvee_{\delta_{n}^{\prime} \in S_{n}^{P^{\prime}}} \delta_{n}^{\prime} \in K^{\prime}$

Corollary 2. Let $n \in \mathbb{N}$. Let $\phi^{\prime} \in \mathcal{L}^{\prime}$ be such that $\operatorname{deg}\left(\phi^{\prime}\right) \leq n$ and let $P^{\prime}$ be the propositional letters appearing in $\phi^{\prime}$. Then, there is $S^{\prime} \subseteq S_{n}^{P^{\prime}}$ (possibly empty) such that $\phi^{\prime} \leftrightarrow \bigvee_{\delta^{\prime} \in S^{\prime}} \delta^{\prime} \in K^{\prime}$ 


\section{Epistemic planning}

In this section, we address Question 2 of the introduction. We start in Section 4.1 by addressing Question 2)a). We first deal with epistemic events (Section 4.1.1), then ontic events (Section 4.1.2), and we eventually generalize our results to other logics than $\mathrm{K}$ (Section 4.1.3). Then, in Section 4.2, we address Question 2)b). Finally, in Section 4.3, we provide an example of epistemic planning.

\subsection{Definition and axiomatization of $\phi, \phi^{\prime \prime} \stackrel{2}{=} \phi^{\prime}$}

Definition 11 (Inference relation $\left.\phi, \phi^{\prime \prime} \models^{2} \phi^{\prime}\right)$. Let $\phi, \phi^{\prime \prime} \in \mathcal{L}$ and $\phi^{\prime} \in \mathcal{L}^{\prime}$. The inference relation $\phi, \phi^{\prime \prime} \stackrel{2}{=}^{\prime} \phi^{\prime}$ is defined as follows:

$\phi,\left.\phi^{\prime \prime}\right|^{2} \phi^{\prime}$ iff for all pointed $\mathcal{L}$-models $(\mathcal{M}, w)$, and $\left(\mathcal{M}^{\prime \prime}, w^{\prime \prime}\right)$ such that $\mathcal{M}, w \models$ $\phi$ and $\mathcal{M}^{\prime \prime}, w^{\prime \prime} \models \phi^{\prime \prime}$, for all pointed $\mathcal{L}^{\prime}$-model $\left(\mathcal{M}^{\prime}, w^{\prime}\right)$ such that $\mathcal{M}, w \models \operatorname{Pre}\left(w^{\prime}\right)$ and $(\mathcal{M}, w) \otimes\left(\mathcal{M}^{\prime}, w^{\prime}\right)$ is bisimilar to $\left(\mathcal{M}^{\prime \prime}, w^{\prime \prime}\right)$, it holds that $\mathcal{M}^{\prime}, w^{\prime}=\phi^{\prime}$

The following proposition states that $\phi, \phi^{\prime} \models \phi^{\prime \prime}$ defined in (Aucher, 2011) and $\phi,\left.\phi^{\prime \prime}\right|^{2} \phi^{\prime}$ are in fact interdefinable. This also shows that the somehow complex definition of $\phi, \phi^{\prime \prime} \models^{2} \phi^{\prime}$ can be simplified into a more compact definition.

Proposition 3. Let $\phi, \phi^{\prime \prime} \in \mathcal{L}$ and $\phi^{\prime} \in \mathcal{L}^{\prime}$.

$\phi, \phi^{\prime \prime} \stackrel{2}{=}^{\prime} \quad$ iff $\quad \phi, \neg \phi^{\prime} \models \neg \phi^{\prime \prime}$

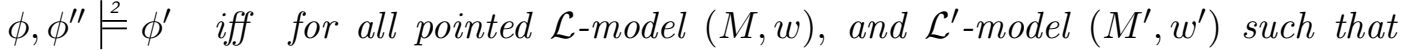
$M, w=\operatorname{Pre}\left(w^{\prime}\right)$, if $M, w \models \phi$ and $(M, w) \otimes\left(M^{\prime}, w^{\prime}\right) \models \phi^{\prime \prime}$ then $M^{\prime}, w^{\prime}=\phi^{\prime}$

Proof. The DEL-sequent $\phi, \phi^{\prime \prime} \models^{2} \phi^{\prime}$ does not hold

iff there are two pointed $\mathcal{L}$-models $(M, w)$ and $\left(M^{\prime \prime}, w^{\prime \prime}\right)$ such that $M, w \models \phi$ and $M^{\prime \prime}, w^{\prime \prime} \models \phi^{\prime \prime}$ and there is a pointed $\mathcal{L}^{\prime}$-model $\left(M^{\prime}, w^{\prime}\right)$ such that $M, w \models \operatorname{Pre}\left(w^{\prime}\right)$ and $(M, w) \otimes\left(M^{\prime}, w^{\prime}\right)$ is bisimilar to $\left(M^{\prime \prime}, w^{\prime \prime}\right)$ and $M^{\prime}, w^{\prime} \models \neg \phi^{\prime}$

iff there are two pointed $\mathcal{L}$-models $(M, w)$ and $\left(M^{\prime \prime}, w^{\prime \prime}\right)$ and there is a pointed $\mathcal{L}^{\prime}$-model $\left(M^{\prime}, w^{\prime}\right)$ such that $M, w \models \operatorname{Pre}\left(w^{\prime}\right), M, w \models \phi, M^{\prime \prime}, w^{\prime \prime} \models \phi^{\prime \prime}, M^{\prime}, w^{\prime} \models \neg \phi^{\prime}$ and $(M, w) \otimes\left(M^{\prime}, w^{\prime}\right)$ is bisimilar to $\left(M^{\prime \prime}, w^{\prime \prime}\right)$.

iff there is a pointed $\mathcal{L}$-model and a pointed $\mathcal{L}^{\prime}$-model $\left(M^{\prime}, w^{\prime}\right)$ such that $M, w \models$

$\operatorname{Pre}\left(w^{\prime}\right), M, w=\phi,(M, w) \otimes\left(M^{\prime}, w^{\prime}\right) \models \phi^{\prime \prime}$ and $M^{\prime}, w^{\prime} \models \neg \phi^{\prime}$.

iff $\phi, \neg \phi^{\prime} \models \neg \phi^{\prime \prime}$ does not hold.

\subsubsection{The case of epistemic events}

We provide two equivalent sequent calculi which axiomatize the inference relation $\phi,\left.\phi^{\prime \prime}\right|^{2}=\phi^{\prime}$. As explained in detail in the proof of Theorem 3, Proposition 3 allows us to easily transfer the results obtained for Question 1)a) in (Aucher, 2011) to answer Question 2)a).

Definition 12 (DEL-Sequent Calculus SC ${ }^{2}$ ). The DEL-Sequent Calculus $\mathrm{SC}^{2}$ is defined by the following axiom schemata and inference rules. Below, $\perp$ (resp. $T$ ) stands for any $\mathrm{K}$-inconsistent formula (resp. K-theorem), and $\perp^{\prime}$ (resp. $\mathrm{T}^{\prime}$ ) stands for any $\mathrm{K}^{\prime}$ inconsistent formula (resp. $\mathrm{K}^{\prime}$-theorem). 


$$
\begin{gathered}
\perp,\left.\phi^{\prime \prime}\right|^{2} \phi^{\prime} \quad \mathrm{A}_{1} \quad \phi,\left.\phi^{\prime \prime}\right|^{2} \top^{\prime} \quad \mathrm{A}_{2} \quad \phi,\left.\perp\right|^{2} \phi^{\prime} \quad \mathrm{A}_{3} \\
p,\left.\neg p\right|^{2} \perp^{\prime} \quad \mathrm{A}_{4} \quad \neg p,\left.p\right|^{2} \perp^{\prime} \quad \mathrm{A}_{5} \quad \neg \operatorname{Pre}\left(p^{\prime}\right),\left.\top\right|^{2} \neg p^{\prime} \quad \mathrm{A}_{6} \\
\frac{\phi,\left.\neg \phi^{\prime \prime}\right|^{2} \phi^{\prime} \quad \phi,\left.\phi^{\prime \prime} \wedge \psi^{\prime \prime}\right|^{2} \phi^{\prime}}{\phi,\left.\psi^{\prime \prime}\right|^{2} \phi^{\prime}} \mathrm{R}_{1} \frac{\phi \wedge \psi,\left.\phi^{\prime \prime}\right|^{2} \phi^{\prime} \neg \psi,\left.\phi^{\prime \prime}\right|^{2} \phi^{\prime}}{\phi,\left.\phi^{\prime \prime}\right|^{2} \phi^{\prime}} \mathrm{R}_{2} \\
\frac{\phi,\left.\phi^{\prime \prime}\right|^{2} \psi^{\prime} \quad \phi,\left.\phi^{\prime \prime}\right|^{2} \psi^{\prime} \rightarrow \phi^{\prime}}{\phi,\left.\phi^{\prime \prime}\right|^{2} \phi^{\prime}} \mathrm{R}_{3} \frac{\phi,\left.\phi^{\prime \prime}\right|^{2} \phi^{\prime}}{B_{j} \phi,\left.\left\langle B_{j}\right\rangle \phi^{\prime \prime}\right|^{2}\left\langle B_{j}\right\rangle \phi^{\prime}} \mathrm{R}_{4} \\
\frac{\phi,\left.\phi^{\prime \prime}\right|^{2}}{\left\langle\phi_{j}\right\rangle\left(\phi \wedge \operatorname{Pre}\left(p^{\prime}\right)\right),\left.B_{j} \phi^{\prime \prime}\right|^{2} B_{j}\left(p^{\prime} \rightarrow \phi^{\prime}\right)} \mathrm{R}_{5}
\end{gathered}
$$

Definition 13 (DEL-Sequent Calculus $\mathrm{SC}^{2 *}$ ). The DEL-Sequent Calculus $\mathrm{SC}^{2 *}$ is defined by the following axiom schemata and inference rules, together with the axiom schemata $A_{2}$ and $A_{6}$ and inference rules $R_{4}$ and $R_{5}$ of the DEL-Sequent Calculus SC ${ }^{2}$. Below, $\phi_{p}$ stands for any propositional formula.

$$
\begin{aligned}
& \phi_{p},\left.\neg \phi_{p}\right|^{2^{*}} \perp^{\prime} \quad \mathrm{A}_{7} \quad \frac{\phi, \phi^{\prime \prime}\left|2^{2^{*}} \phi^{\prime} \quad \phi, \psi^{\prime \prime}\right|^{2^{*}} \phi^{\prime}}{\phi,\left.\phi^{\prime \prime} \vee \psi^{\prime \prime}\right|^{2^{*}} \phi^{\prime}} \mathrm{R}_{6} \\
& \frac{\phi,\left.\phi^{\prime \prime}\right|^{2^{*}} \phi^{\prime} \quad \phi,\left.\phi^{\prime \prime}\right|^{2^{*}} \psi^{\prime}}{\phi,\left.\phi^{\prime \prime}\right|^{2^{*}} \phi^{\prime} \wedge \psi^{\prime}} \mathrm{R}_{7} \frac{\phi,\left.\phi^{\prime \prime}\right|^{2^{*}} \phi^{\prime} \quad \psi,\left.\phi^{\prime \prime}\right|^{2^{*}} \phi^{\prime}}{\phi \vee \psi,\left.\phi^{\prime \prime}\right|^{2^{*}} \phi^{\prime}} \mathrm{R}_{8} \\
& \frac{\phi,\left.\phi^{\prime \prime}\right|^{2^{*}} \phi^{\prime}}{\psi,\left.\psi^{\prime \prime}\right|^{2^{*}} \phi^{\prime}} \mathrm{R}_{9} \quad \frac{\phi,\left.\phi^{\prime \prime}\right|^{2^{*}} \phi^{\prime}}{\phi,\left.\phi^{\prime \prime}\right|^{2^{*}} \psi^{\prime}} \mathrm{R}_{10}
\end{aligned}
$$

where $\psi \rightarrow \phi, \psi^{\prime \prime} \rightarrow \phi^{\prime \prime} \in \mathrm{K} \quad$ where $\phi^{\prime} \rightarrow \psi^{\prime} \in \mathrm{K}^{\prime}$.

Theorem 3 (Soundness and completeness of $\mathrm{SC}^{2}$ and $\mathrm{SC}^{2^{*}}$ ). Let $\phi, \phi^{\prime \prime} \in \mathcal{L}$ and $\phi^{\prime} \in \mathcal{L}^{\prime}$. It holds that $\phi, \phi^{\prime \prime} \models^{2} \phi^{\prime}$ if and only if $\phi,\left.\phi^{\prime \prime}\right|^{2} \phi^{\prime}$. It also holds that $\phi, \phi^{\prime \prime} \models^{2} \phi^{\prime}$ if and only if $\phi, \phi^{\prime \prime} \stackrel{2}{ }^{*} \phi^{\prime}$.

Proof. One proves by induction on the number $n$ of inference rules used in a derivation that for all $\phi, \phi^{\prime \prime} \in \mathcal{L}$ and $\phi^{\prime} \in \mathcal{L}^{\prime}$, it holds that $\phi,\left.\phi^{\prime \prime}\right|^{2} \phi^{\prime}$ if and only if $\phi, \neg \phi^{\prime} \vdash \neg \phi^{\prime \prime}$ (resp. $\phi,\left.\phi^{\prime \prime}\right|^{2^{*}} \phi^{\prime}$ if and only if $\phi,\left.\phi^{\prime \prime}\right|^{*} \phi^{\prime}$ ). The base case $n=0$ holds because the axioms of $\mathrm{SC}^{2}$ (resp. $\mathrm{SC}^{2^{*}}$ ) are defined this way. The induction step also holds because the rules of $\mathrm{SC}^{2}$ (resp. $\mathrm{SC}^{2^{*}}$ ) are also all defined according to this logical relationship. Therefore, it holds that $\phi,\left.\phi^{\prime \prime}\right|^{2} \phi^{\prime}$

iff $\phi, \neg \phi^{\prime} \vdash \neg \phi^{\prime \prime}$,

iff $\phi, \neg \phi^{\prime} \models \neg \phi^{\prime \prime}$ by soundness and completeness of the DEL-sequent calculus SC of

(Aucher, 2011), 
iff $\phi, \phi^{\prime} \stackrel{2}{=}^{\prime \prime}$ by Proposition 3 .

The same reasoning applies to $\phi, \phi^{\prime \prime} \stackrel{2^{*}}{\underline{2}} \phi^{\prime}$

Theorem 4. (Aucher et al., 2011, 2012) Given some formulas $\phi, \phi^{\prime \prime} \in \mathcal{L}$ and $\phi^{\prime} \in \mathcal{L}^{\prime}$, the problem of determining whether $\phi,\left.\phi^{\prime \prime}\right|^{2} \phi^{\prime}$ holds is decidable and NEXPTIMEcomplete.

\subsubsection{The case of ontic events}

Just as in the companion paper (Aucher, 2011), to deal with ontic events, we associate to each propositional variable $p^{\prime} \in \Phi^{\prime}$ a substitution function $\operatorname{Sub}\left(p^{\prime}\right): \Phi \rightarrow \mathcal{L}$. Intuitively, $\operatorname{Sub}\left(p^{\prime}\right)(p)$ is a sufficient and necessary condition before the occurrence of $p^{\prime}$ for $p$ to be true after the occurrence of $p^{\prime}$. This substitution function induces a substitution function $\operatorname{Sub}\left(M^{\prime}, w^{\prime}\right)$ over pointed $\mathcal{L}^{\prime}$-models $\left(M^{\prime}, w^{\prime}\right)$ :

$$
\operatorname{Sub}\left(M^{\prime}, w^{\prime}\right)(p)= \begin{cases}\operatorname{Sub}\left(p^{\prime}\right)(p) & \text { if } M^{\prime}, w^{\prime} \models p^{\prime} \text { for some } p^{\prime} \in \Phi^{\prime} \\ p & \text { otherwise. }\end{cases}
$$

Then, the new valuation of Equation 4 in Definition 8 is defined as follows:

$$
V^{\otimes}(p)=\left\{\left(v, v^{\prime}\right) \in W^{\otimes} \mid M, v \models \operatorname{Sub}\left(M^{\prime}, v^{\prime}\right)(p)\right\} .
$$

One can easily show that this new definition of the product update is axiomatized by replacing axiom schemata $A_{4}$ and $A_{5}$ by the following axiom schemata:

$$
\begin{array}{ll}
\mathrm{A}_{4}^{\prime} & \operatorname{Sub}\left(p^{\prime}\right)(p), \neg p \\
\mathrm{~A}_{5}^{\prime} & \neg \operatorname{Sub}\left(p^{\prime}\right)(p), p p^{\prime} \neg p^{\prime}
\end{array}
$$

\subsubsection{Extension to other logics}

Just as in (Aucher, 2011), all the results of this section can be extended to other logics than $\mathrm{K}$ and $\mathrm{K}^{\prime}$ in case the class of frames these logics define is stable for the product update.

Let $\mathcal{C}$ be a class of $\mathcal{L}$-models and $\mathcal{C}^{\prime}$ be a class of $\mathcal{L}^{\prime}$-models. $\mathcal{C}$ is stable for the product update with respect to the class $\mathcal{C}^{\prime}$ when for all $M \in \mathcal{C}$ and all $M^{\prime} \in \mathcal{C}^{\prime}$, for all $w \in M$ and all $w^{\prime} \in M^{\prime}$ such that $M, w \models \operatorname{Pre}\left(w^{\prime}\right),(M, w) \otimes\left(M^{\prime}, w^{\prime}\right)$ is a pointed $\mathcal{L}$-model of $\mathcal{C} .^{1}$

Let $\mathcal{C}$ be a class of $\mathcal{L}$-models and let $\mathcal{C}^{\prime}$ be a class of $\mathcal{L}^{\prime}$-models. The inference relation $\phi, \phi^{\prime \prime} \frac{2}{\overline{\mathcal{C}, \mathcal{C}^{\prime}}} \phi^{\prime}$ is defined as follows:

$\phi, \phi^{\prime \prime} \stackrel{2}{\frac{\mathcal{C}, \mathcal{C}^{\prime}}{\phi^{\prime}}} \phi^{\prime} \quad$ iff $\quad$ for all pointed $\mathcal{L}$-model $(M, w)$ of $\mathcal{C}$, and $\mathcal{L}^{\prime}$-model $\left(M^{\prime}, w^{\prime}\right)$ of $\mathcal{C}^{\prime}$ such that $M, w \models \operatorname{Pre}\left(w^{\prime}\right)$, if $M, w \models \phi$ and $(M, w) \otimes\left(M^{\prime}, w^{\prime}\right) \models$ $\phi^{\prime \prime}$ then $M^{\prime}, w^{\prime}=\phi^{\prime}$.

Let $\mathrm{L}$ be a logic for the language $\mathcal{L}$ containing $\mathrm{K}$, and let $\mathrm{L}^{\prime}$ be a logic for the language $\mathcal{L}^{\prime}$ containing $\mathrm{K}^{\prime}$. The DEL-sequent calculus $S C_{L, L^{\prime}}^{2}$ is defined as the DEL-sequent calculus $\mathrm{SC}^{2}$, except that the logic $\mathrm{K}$ and $\mathrm{K}^{\prime}$ are replaced by the logic $\mathrm{L}$ and $\mathrm{L}^{\prime}$ respectively.

Theorem 5. Let $L$ be a logic sound and complete for $\mathcal{L}$ with respect to a class $\mathcal{C}$ of $\mathcal{L}$-models and let $L^{\prime}$ be a logic sound and complete for $\mathcal{L}^{\prime}$ with respect to a class $\mathcal{C}^{\prime}$ of

\footnotetext{
${ }^{1}$ As noted in (van Benthem, 2007), the only first-order frame conditions that are stable for the product update are those definable as universal Horn sentences. Reflexivity, symmetry, and transitivity are of this special form.
} 
$\mathcal{L}^{\prime}$-models. If $\mathcal{C}$ is stable for the product update with respect to the class $\mathcal{C}^{\prime}$, then for all $\phi, \phi^{\prime \prime} \in \mathcal{L}$ and all $\phi^{\prime} \in \mathcal{L}^{\prime}$, it holds that $\phi, \phi^{\prime \prime} \frac{2}{\overline{\mathcal{C}, \mathcal{C}^{\prime}}} \phi^{\prime}$ if and only if $\phi, \phi^{\prime \prime} \frac{2}{L, L^{\prime}} \phi^{\prime}$.

\subsection{Epistemic planning from $(M, w)$ to $\phi^{\prime \prime}$ and epistemic planning from $\phi$ to $\phi^{\prime \prime}$}

Just as for the axiomatization of $\phi, \phi^{\prime} \vdash \phi^{\prime \prime}$, the axiomatization of $\phi,\left.\phi^{\prime \prime}\right|^{2} \phi^{\prime}$ provides us with a means to compute all the necessary properties $\phi^{\prime}$ that an event should fulfill so that its occurrence in any situation where $\phi$ holds yields a situation where $\phi^{\prime \prime}$ holds. However, we could wonder if there is a more compact way to represent all these properties $\phi^{\prime}$. This is what we will show in this section by introducing the notion of epistemic planning from $\phi$ to $\phi^{\prime \prime}: \phi Q_{P^{\prime}} \phi^{\prime \prime}$.

We build the epistemic planning operator $\phi \theta_{P^{\prime}} \phi^{\prime \prime}$ step by step. We start by defining an epistemic planning operator $(M, w) \Theta_{P^{\prime}} \phi^{\prime \prime}$ between a pointed $\mathcal{L}$-model and a formula $\phi^{\prime \prime} \in \mathcal{L}$. Then, we extrapolate this definition and define the epistemic planning operator $\delta \theta_{P^{\prime}} \phi^{\prime \prime}$ between a Kit Fine formula $\delta$ and a formula $\phi^{\prime \prime} \in \mathcal{L}$, the formula $\delta$ somehow representing a pointed $\mathcal{L}$-model $(M, w)$. Finally, we build on this definition to define the full operator $\phi \Theta_{P^{\prime}} \phi^{\prime \prime}$, relying on the fact that any formula $\phi \in \mathcal{L}$ can be equivalently decomposed into a disjunction of Kit Fine formulas $\delta$ s.

\subsubsection{Epistemic planning from $(M, w)$ to $\phi^{\prime \prime}$}

Definition 14 (Epistemic planning from $(M, w)$ to $\phi)$. Let $(M, w)$ be a pointed $\mathcal{L}$ model, let $\phi^{\prime \prime} \in \mathcal{L}$ and let $P^{\prime}$ be a finite subset of $\Phi^{\prime}$. The epistemic planning from $(M, w)$ to $\phi^{\prime \prime}$, which we write $(M, w) \otimes_{P^{\prime}} \phi^{\prime \prime}$, is the formula of $\mathcal{L}^{\prime}$ defined inductively as follows:

$$
\begin{aligned}
(M, w) \otimes_{P^{\prime}} p & = \begin{cases}q_{w}^{\prime} & \text { if } M, w \models p \\
\perp & \text { otherwise }\end{cases} \\
(M, w) \otimes_{P^{\prime}}\left(\phi^{\prime \prime} \wedge \psi^{\prime \prime}\right) & =\left((M, w) \otimes_{P^{\prime}} \phi^{\prime \prime}\right) \wedge\left((M, w) \otimes_{P^{\prime}} \psi^{\prime \prime}\right) \\
(M, w) \ominus_{P^{\prime}} \neg \phi^{\prime \prime} & =q_{w}^{\prime} \wedge \neg\left((M, w) \vartheta_{P^{\prime}} \phi^{\prime \prime}\right) \\
(M, w) \otimes_{P^{\prime}} B_{j} \phi^{\prime \prime} & =q_{w}^{\prime} \wedge \bigwedge_{v \in R_{j}(w)} B_{j}\left(q_{v}^{\prime} \rightarrow(M, v) \otimes_{P^{\prime}} \phi^{\prime \prime}\right) .
\end{aligned}
$$

where $q_{w}^{\prime}=\bigvee\left\{p^{\prime} \in P^{\prime} \mid M, w \models \operatorname{Pre}\left(p^{\prime}\right)\right\}$.

Note that the above definition can easily be turned into an algorithm taking as input an $\mathcal{L}$-model $(M, w)$ and an epistemic goal $\phi^{\prime \prime}$, and yielding as output the formula $(M, w) \otimes_{P^{\prime}} \phi^{\prime \prime}$. Theorem 6 below provides an alternative and non-constructive definition of $(M, w) \otimes_{P^{\prime}} \phi^{\prime \prime}$.

Theorem 6. Let $(M, w)$ be a pointed $\mathcal{L}$-model, let $\phi \in \mathcal{L}$ and let $P^{\prime}$ be a finite subset of $\Phi^{\prime}$. Then, for any $P^{\prime}$-complete $\mathcal{L}^{\prime}$-model $\left(M^{\prime}, w^{\prime}\right)$, it holds that

$$
M^{\prime}, w^{\prime} \models(M, w) \otimes_{P^{\prime}} \phi^{\prime \prime} \quad \text { iff } \quad M, w \models \operatorname{Pre}\left(w^{\prime}\right) \text { and }(M, w) \otimes\left(M^{\prime}, w^{\prime}\right) \models \phi^{\prime \prime}
$$

Definition 14 of $(M, w) Q_{P^{\prime}} \phi^{\prime \prime}$ in Theorem 6 entails that, given an initial situation $(M, w)$, the occurence of any event satisfying the formula $(M, w) \Theta_{P^{\prime}} \phi^{\prime \prime}$ will result in a final situation where $\phi^{\prime \prime}$ holds. This condition $(M, w) Q_{P^{\prime}} \phi^{\prime \prime}$ is not only sufficient but also necessary: any event which does not satisfy the formula $(M, w) \otimes_{P^{\prime}} \phi^{\prime \prime}$ will not lead us to a final situation where $\phi^{\prime \prime}$ holds.

Proof. We prove Theorem 6 by induction on $\phi^{\prime \prime}$. 
- Case $\phi^{\prime \prime}=p$ :

We first prove the implication from left to right. Assume that $M^{\prime}, w^{\prime} \models$ $(M, w) \Theta_{P^{\prime}} p$. Necessarily, $M, w=p$, because otherwise we would have that $M^{\prime}, w^{\prime}=\perp$. Hence, $M^{\prime}, w^{\prime}=q_{w}^{\prime}$, i.e. there is $p^{\prime} \in P^{\prime}$ such that $M, w \models \operatorname{Pre}\left(p^{\prime}\right)$ and $M^{\prime}, w^{\prime} \models p^{\prime}$. Therefore, $M, w \models \operatorname{Pre}\left(w^{\prime}\right)$. Moreover, by definition of the product update (Equation 4), it holds that $(M, w) \otimes\left(M^{\prime}, w^{\prime}\right) \models p$.

Now, we prove the implication from right to left. Assume that $M, w \models \operatorname{Pre}\left(w^{\prime}\right)$ and $(M, w) \otimes\left(M^{\prime}, w^{\prime}\right)=p$. Then, by definition of the product update (Equation 4), it holds that $M, w \models p$. Now, because $\left(M^{\prime}, w^{\prime}\right)$ is $P^{\prime}$-complete, there is $p^{\prime} \in P^{\prime}$ such that $M^{\prime}, w^{\prime} \models p^{\prime}$. Then, $\operatorname{Pre}\left(p^{\prime}\right)=\operatorname{Pre}\left(w^{\prime}\right)$ and because $M, w \models \operatorname{Pre}\left(w^{\prime}\right)$, it holds that $M, w \models \operatorname{Pre}\left(p^{\prime}\right)$. Hence, $M^{\prime}, w^{\prime} \models q_{w}^{\prime}$ because $q_{w}^{\prime}=\bigvee\left\{p^{\prime} \in P^{\prime} \mid M, w \models \operatorname{Pre}\left(p^{\prime}\right)\right\}$. That is, $M^{\prime}, w^{\prime}=(M, w) \otimes_{P^{\prime}} p$.

- Case $\phi^{\prime \prime}=\neg \psi^{\prime \prime}$ :

First, we prove the implication from left to right. Assume that $M^{\prime}, w^{\prime} \models$ $(M, w) \otimes_{P^{\prime}} \neg \psi^{\prime \prime}$. Then, $M^{\prime}, w^{\prime} \models q_{w}^{\prime} \wedge \neg\left((M, w) \otimes_{P^{\prime}} \psi^{\prime \prime}\right)$. Then, because $M^{\prime}, w^{\prime} \models$ $q_{w}^{\prime}$, there is $p^{\prime} \in P^{\prime}$ such that $M^{\prime}, w^{\prime}=p^{\prime}$ and $M, w \models \operatorname{Pre}\left(p^{\prime}\right)$. That is, $M, w \mid=\operatorname{Pre}\left(w^{\prime}\right)$. Moreover, because $M^{\prime}, w^{\prime} \not \models(M, w) \otimes_{P^{\prime}} \psi^{\prime \prime}$, by Induction Hypothesis, it holds that either $M, w \not \models \operatorname{Pre}\left(w^{\prime}\right)$ or $(M, w) \otimes\left(M^{\prime}, w^{\prime}\right) \not \models \psi^{\prime \prime}$. However, because we just proved that $M, w \models \operatorname{Pre}\left(w^{\prime}\right)$, it holds that $(M, w) \otimes\left(M^{\prime}, w^{\prime}\right) \not \models \psi^{\prime \prime}$. That is, $(M, w) \otimes\left(M^{\prime}, w^{\prime}\right) \models \phi^{\prime \prime}$.

Now, we prove the second implication from right to left. Assume that $M, w \models$ $\operatorname{Pre}\left(w^{\prime}\right)$ and $(M, w) \otimes\left(M^{\prime}, w^{\prime}\right) \models \phi^{\prime \prime}$. Then, $(M, w) \otimes\left(M^{\prime}, w^{\prime}\right) \not \models \psi^{\prime \prime}$. Therefore, by Induction Hypothesis, $M^{\prime}, w^{\prime} \not \models(M, w) \theta_{P^{\prime}} \psi^{\prime \prime}$, i.e. $M^{\prime}, w^{\prime} \models \neg\left((M, w) \theta_{P^{\prime}} \psi^{\prime \prime}\right)$. Moreover, because $\left(M^{\prime}, w^{\prime}\right)$ is $P^{\prime}$-complete, there is $p^{\prime} \in P^{\prime}$ such that $M^{\prime}, w^{\prime} \models p^{\prime}$. Besides, $M, w \models \operatorname{Pre}\left(p^{\prime}\right)$, because $\operatorname{Pre}\left(p^{\prime}\right)=\operatorname{Pre}\left(w^{\prime}\right)$. Therefore, $M^{\prime}, w^{\prime} \models$ $\bigvee\left\{p^{\prime} \in P^{\prime} \mid M, w \models \operatorname{Pre}\left(p^{\prime}\right)\right\}$, i.e. $M^{\prime}, w^{\prime} \models \bigvee\left\{p^{\prime} \in P^{\prime}|M, w| \operatorname{Pre}\left(p^{\prime}\right)\right\}$, i.e. $M^{\prime}, w^{\prime}=q_{w}^{\prime}$. Hence, $M^{\prime}, w^{\prime}=q_{w}^{\prime} \wedge \neg\left((M, w) \otimes_{P^{\prime}} \psi^{\prime \prime}\right)$, i.e. $M^{\prime}, w^{\prime}=(M, w) \otimes_{P^{\prime}}$ $\neg \psi^{\prime \prime}$. That is, $M^{\prime}, w^{\prime} \models(M, w) \Theta_{P^{\prime}} \phi^{\prime \prime}$.

- Case $\phi^{\prime \prime}=\phi_{1}^{\prime \prime} \wedge \phi_{2}^{\prime \prime}$ :

We only prove the implication from left to right, the other direction of the implication is proved similarly. Assume that $M^{\prime}, w^{\prime} \models(M, w) \otimes_{P^{\prime}} \phi_{1}^{\prime \prime} \wedge \phi_{2}^{\prime \prime}$. Then, $M^{\prime}, w^{\prime}=(M, w) \otimes_{P^{\prime}} \phi_{1}^{\prime \prime} \wedge(M, w) \otimes_{P^{\prime}} \phi_{2}^{\prime \prime}$ by Definition 14. So, $M^{\prime}, w^{\prime}=(M, w) \otimes_{P^{\prime}} \phi_{1}^{\prime \prime}$ and $M^{\prime}, w^{\prime}=(M, w) \otimes_{P^{\prime}} \phi_{2}^{\prime \prime}$. Then, by Induction Hypothesis, $M, w \models \operatorname{Pre}\left(w^{\prime}\right)$ and $(M, w) \otimes\left(M^{\prime}, w^{\prime}\right) \models \phi_{1}^{\prime \prime}$ and $(M, w) \otimes\left(M^{\prime}, w^{\prime}\right) \models \phi_{2}^{\prime \prime}$. So, $(M, w) \otimes\left(M^{\prime}, w^{\prime}\right) \models \phi_{1}^{\prime \prime} \wedge \phi_{2}^{\prime \prime}$ and $M, w \models \operatorname{Pre}\left(w^{\prime}\right)$.

- Case $\phi^{\prime \prime}=B_{j} \psi^{\prime \prime}$ :

First, we prove the implication from left to right. Assume that $M^{\prime}, w^{\prime} \models$ $(M, w) \otimes_{P^{\prime}} B_{j} \psi^{\prime \prime}$, i.e. $M^{\prime}, w^{\prime} \models q_{w}^{\prime} \wedge \bigwedge_{v \in R_{j}(w)} B_{j}\left(q_{v}^{\prime} \rightarrow(M, v) \otimes_{P^{\prime}} \psi^{\prime \prime}\right)$. Because $M^{\prime}, w^{\prime}=q_{w}^{\prime}$, there is $p^{\prime} \in P^{\prime}$ such that $M, w \models \operatorname{Pre}\left(p^{\prime}\right)$ and $M^{\prime}, w^{\prime}=p^{\prime}$. Therefore, $M, w \models \operatorname{Pre}\left(w^{\prime}\right)$. Now, let $v \in R_{j}(w)$ and $v^{\prime} \in R_{j}\left(w^{\prime}\right)$ such that $M, v=\operatorname{Pre}\left(v^{\prime}\right)$. Then, because $M^{\prime}$ is $P^{\prime}$-complete, there is $p^{\prime} \in P^{\prime}$ such that $M^{\prime}, v^{\prime} \models p^{\prime}$. Therefore, $\operatorname{Pre}\left(v^{\prime}\right)=\operatorname{Pre}\left(p^{\prime}\right)$ and $M^{\prime}, v^{\prime} \models q_{v}^{\prime}$. Now, because $M^{\prime}, w^{\prime}=B_{j}\left(q_{v}^{\prime} \rightarrow(M, v) \otimes_{P^{\prime}} \psi^{\prime \prime}\right)$ for all $v \in R_{j}(w)$, it holds that $M^{\prime}, w^{\prime} \models$ $q_{v}^{\prime} \rightarrow(M, w) \otimes_{P^{\prime}} \psi^{\prime \prime}$. Hence, $M^{\prime}, v^{\prime}=\left(M^{\prime}, v^{\prime}\right) \otimes_{P^{\prime}} \psi^{\prime \prime}$. Then, by Induction Hypothesis, $(M, v) \otimes\left(M^{\prime}, v^{\prime}\right) \models \psi^{\prime \prime}$, and so for all $\left(v, v^{\prime}\right) \in R_{j}\left(w, w^{\prime}\right)$. Therefore, $(M, w) \otimes\left(M^{\prime}, w^{\prime}\right) \models B_{j} \psi^{\prime \prime}$, i.e. $(M, w) \otimes\left(M^{\prime}, w^{\prime}\right) \models \phi^{\prime \prime}$.

Second, we prove the implication from right to left. Assume that $M, w \models$ $\operatorname{Pre}\left(w^{\prime}\right)$ and $(M, w) \otimes\left(M^{\prime}, w^{\prime}\right) \models B_{j} \psi^{\prime \prime}$. Because $M^{\prime}$ is $P^{\prime}$-complete, there is $p^{\prime} \in P^{\prime}$ such that $M^{\prime}, w^{\prime} \models p^{\prime}$. Therefore, $M^{\prime}, w^{\prime} \models q_{w}^{\prime}$, because $\operatorname{Pre}\left(p^{\prime}\right)=\operatorname{Pre}\left(w^{\prime}\right)$. Now, let $v \in R_{j}(w)$ and let $v^{\prime} \in R_{j}\left(w^{\prime}\right)$. We are going to prove that $M^{\prime}, v^{\prime}=q_{v}^{\prime} \rightarrow$ $(M, v) \otimes_{P^{\prime}} \psi^{\prime \prime}$. Assume that $M^{\prime}, v^{\prime}=q_{v}^{\prime}$. Then, there is $p^{\prime} \in P^{\prime}$ such that $M^{\prime}, v^{\prime}=p^{\prime}$ 
and $M, v \models \operatorname{Pre}\left(p^{\prime}\right)$. Then, $M, v \models \operatorname{Pre}\left(v^{\prime}\right)$ (1) because $\operatorname{Pre}\left(v^{\prime}\right)=\operatorname{Pre}\left(p^{\prime}\right)$. Moreover, $(M, v) \otimes\left(M^{\prime}, v^{\prime}\right) \models \psi^{\prime \prime}(2)$ because $(M, w) \otimes\left(M^{\prime}, w^{\prime}\right) \models B_{j} \psi^{\prime \prime}$, because of (1) and (2). Therefore, $M^{\prime}, v^{\prime}=q_{v}^{\prime} \rightarrow(M, v) \otimes_{P^{\prime}} \psi^{\prime \prime}$, and so for all $v^{\prime} \in R_{j}\left(w^{\prime}\right)$ and $v \in R_{j}(w)$. So, finally, $M^{\prime}, w^{\prime} \models \bigwedge_{v \in R_{j}(w)} B_{j}\left(q_{v}^{\prime} \rightarrow(M, v) \otimes_{P^{\prime}} \psi^{\prime \prime}\right)$.

Hence, $M^{\prime}, w^{\prime} \models(M, w) \otimes_{P^{\prime}} B_{j} \psi^{\prime \prime}$, because we already proved that $M^{\prime}, w^{\prime} \models q_{w}^{\prime}$. That is, $M^{\prime}, w^{\prime}=(M, w) \otimes_{P^{\prime}} \phi^{\prime \prime}$.

\subsubsection{Epistemic planning from $\phi$ to $\phi^{\prime \prime}$}

We can generalize the notion of epistemic planning from $(M, w)$ to $\phi^{\prime \prime}$ by considering that the initial situation is incompletely described by a formula $\phi$. This leads us to define the notion of epistemic planning from $\phi$ to $\phi^{\prime \prime}$.

Definition 15 (Epistemic planning from $\phi$ to $\phi^{\prime \prime}$ ). Let $\phi, \phi^{\prime \prime} \in \mathcal{L}$ and let $P^{\prime}$ be a finite subset of $\Phi^{\prime}$. Let $n=\max \left\{\operatorname{deg}(\phi), \operatorname{deg}\left(\phi^{\prime \prime}\right)\right\}$ and $N=\max \left\{\operatorname{deg}\left(\operatorname{Pre}\left(p^{\prime}\right)\right) \mid p^{\prime} \in P^{\prime}\right\}$. Then, by Corollary 1, there is $S \subseteq S_{n+N}$ such that $\phi \leftrightarrow \bigvee_{\delta \in S} \delta \in \mathrm{K}$. The epistemic planning from $\phi$ to $\phi^{\prime \prime}$, which we write $\phi Q_{P^{\prime}} \phi^{\prime \prime}$, is the formula of $\mathcal{L}^{\prime}$ defined as follows:

$$
\phi \otimes_{P^{\prime}} \phi^{\prime \prime}=\bigvee\left\{\delta \otimes_{P^{\prime}} \phi^{\prime \prime} \mid \delta \in S\right\}
$$

where, for all $\delta \in S_{k+N}$ with $k \leq n$ and all $\phi^{\prime \prime} \in \mathcal{L}$, the formula $\delta \theta_{P^{\prime}} \phi^{\prime \prime}$ is defined inductively as follows:

$$
\begin{aligned}
\delta \vartheta_{P^{\prime}} p & =\left\{\begin{array}{l}
q_{\delta}^{\prime} \text { if } \delta \rightarrow p \in \mathrm{K} \\
\perp \text { otherwise. }
\end{array}\right. \\
\delta \vartheta_{P^{\prime}}\left(\phi^{\prime \prime} \wedge \psi^{\prime \prime}\right) & =\left(\delta \vartheta_{P^{\prime}} \phi^{\prime \prime}\right) \wedge\left(\delta \vartheta_{P^{\prime}} \psi^{\prime \prime}\right) \\
\delta \vartheta_{P^{\prime}} \neg \phi^{\prime \prime} & =q_{\delta}^{\prime} \wedge \neg\left(\delta \Theta_{P^{\prime}} \phi^{\prime \prime}\right) \\
\delta \otimes_{P^{\prime}} B_{j} \phi^{\prime \prime} & =q_{\delta}^{\prime} \wedge \bigwedge_{\delta_{j} \in R_{j}(\delta)} B_{j}\left(q_{\delta_{j}}^{\prime} \rightarrow \delta_{j} \otimes_{P^{\prime}} \phi^{\prime \prime}\right) .
\end{aligned}
$$

where $q_{\delta}^{\prime}=\bigvee\left\{p^{\prime} \in P^{\prime} \mid \delta \rightarrow \operatorname{Pre}\left(p^{\prime}\right) \in \mathrm{K}\right\}$.

The following theorem provides an alternative and non-constructive definition of the formula $\phi Q_{P^{\prime}} \phi^{\prime \prime}$ of $\mathcal{L}^{\prime}$.

Theorem 7. Let $\phi, \phi^{\prime \prime} \in \mathcal{L}$ and let $P^{\prime}$ be a finite subset of $\Phi^{\prime}$. Then, for all $P^{\prime}$-complete $\mathcal{L}^{\prime}$-model $\left(M^{\prime}, w^{\prime}\right)$, it holds that

$$
M^{\prime}, w^{\prime} \models \phi \otimes_{P^{\prime}} \phi^{\prime \prime} \quad \text { iff } \quad \begin{aligned}
& \text { there is }(M, w) \text { such that } M, w \models \phi, \\
& M, w \models \operatorname{Pre}\left(w^{\prime}\right) \text { and }(M, w) \otimes\left(M^{\prime}, w^{\prime}\right) \models \phi^{\prime \prime}
\end{aligned}
$$

Note that we could define a dual operator of $\phi Q_{P^{\prime}} \phi^{\prime \prime}$ as follows:

$$
\phi[\Theta]_{P^{\prime}} \phi^{\prime \prime} \triangleq \neg\left(\phi \theta_{P^{\prime}} \neg \phi^{\prime \prime}\right)
$$

The counterpart of Theorem 7 for this dual operator is as follows:

$$
\begin{aligned}
M^{\prime}, w^{\prime} \models \phi[\otimes]_{P^{\prime}} \phi^{\prime \prime} \quad \text { iff } \quad \text { for all }(M, w) \text { such that } M, w \models \phi, \\
\text { if } M, w \models \operatorname{Pre}\left(w^{\prime}\right) \text { then }(M, w) \otimes\left(M^{\prime}, w^{\prime}\right) \models \phi^{\prime \prime}
\end{aligned}
$$


This definition entails that, given any initial situation satisfying $\phi$, any event satisfying $\phi[\theta]_{P^{\prime}} \phi^{\prime \prime}$ occurring in this initial situation will result in a new situation where $\phi^{\prime \prime}$ holds:

$$
\phi,\left.\phi[\theta]_{P^{\prime}} \phi^{\prime \prime}\right|_{\kappa^{\mathrm{P}^{\prime}}} \phi^{\prime \prime}
$$

To prove Theorem 7 , we first prove the following lemma.

Lemma 1. Let $\phi^{\prime \prime} \in \mathcal{L}$ and let $P^{\prime}$ be a finite subset of $\Phi^{\prime}$. Let $N=$ $\max \left\{\operatorname{deg}\left(\operatorname{Pre}\left(p^{\prime}\right)\right) \mid p^{\prime} \in P^{\prime}\right\}$ and $n=\operatorname{deg}\left(\phi^{\prime \prime}\right)$. Then, for all pointed $\mathcal{L}$-model $(M, w)$, for all $\delta \in S_{n+N}$ such that $M, w \models \delta$, it holds that $(M, w) \otimes_{P^{\prime}} \phi^{\prime \prime} \leftrightarrow \delta \otimes_{P^{\prime}} \phi^{\prime \prime} \in K^{P^{\prime}}$.

Proof. We prove Lemma 1 by induction on the number of symbols in $\phi^{\prime \prime}$, that is $\left|\phi^{\prime \prime}\right|$. Our induction hypothesis is $\mathcal{P}(k)$ : "for all $\phi^{\prime \prime} \in \mathcal{L}$ such that $\left|\phi^{\prime \prime}\right|=k$, for all $\delta \in S_{n+N}$ (where $n=\operatorname{deg}\left(\phi^{\prime \prime}\right)$ ), and for all pointed $\mathcal{L}$-model $(M, w)$ such that $M, w \models \delta$, it holds that $(M, w) \otimes_{P^{\prime}} \phi^{\prime \prime} \leftrightarrow \delta \otimes_{P^{\prime}} \phi^{\prime \prime} \in \mathrm{K}^{\mathrm{P}^{\prime} "}$.

- Case $\phi^{\prime \prime}=p$ :

If $M, w \models p$, then $\delta \rightarrow p \in \mathrm{K}$ and $(M, w) \ominus_{P^{\prime}} p=q_{w}^{\prime}=\bigvee\left\{p^{\prime} \in P^{\prime} \mid M, w \models\right.$ $\left.\operatorname{Pre}\left(p^{\prime}\right)\right\}=\bigvee\left\{p^{\prime} \in P^{\prime} \mid \delta \rightarrow \operatorname{Pre}\left(p^{\prime}\right) \in \mathrm{K}\right\}$ because $M, w \models \delta$. So, $(M, w) \otimes_{P^{\prime}} p=$ $q_{\delta}^{\prime}=\delta \otimes_{P^{\prime}} p$. If $M, w \not \models p$, then $\delta \rightarrow p \notin \mathrm{K}$, and $(M, w) \otimes_{P^{\prime}} p=\perp=\delta \otimes_{P^{\prime}} p$.

So, in both cases, $(M, w) \vartheta_{P^{\prime}} p \leftrightarrow \delta \otimes_{P^{\prime}} p \in \mathrm{K}^{\mathrm{P}^{\prime}}$.

- Case $\phi^{\prime \prime}=\phi_{1}^{\prime \prime} \wedge \phi_{2}^{\prime \prime}$ :

$(M, w) \theta_{P^{\prime}}\left(\phi_{1}^{\prime \prime} \wedge \phi_{2}^{\prime \prime}\right)=\left((M, w) \theta_{P^{\prime}} \phi_{1}^{\prime \prime}\right) \wedge\left((M, w) \theta_{P^{\prime}} \phi_{2}^{\prime \prime}\right)$ by definition. So, $(M, w) Q_{P^{\prime}}\left(\phi_{1}^{\prime \prime} \wedge \phi_{2}^{\prime \prime}\right)=\left(\delta \otimes_{P^{\prime}} \phi_{1}^{\prime \prime}\right) \wedge\left(\delta \otimes_{P^{\prime}} \phi_{2}^{\prime \prime}\right)$ by Induction Hypothesis. Then, $(M, w) \otimes_{P^{\prime}}\left(\phi_{1}^{\prime \prime} \wedge \phi_{2}^{\prime \prime}\right)=\delta \otimes_{P^{\prime}}\left(\phi_{1}^{\prime \prime} \wedge \phi_{2}^{\prime \prime}\right)$ by definition So, $(M, w) \otimes_{P^{\prime}} \phi^{\prime \prime} \leftrightarrow \delta \otimes_{P^{\prime}} \phi^{\prime \prime} \in$ $\mathrm{K}^{\mathrm{P}^{\prime}}$.

- Case $\phi^{\prime \prime}=\neg \psi^{\prime \prime}$ :

$(M, w) \otimes_{P^{\prime}} \neg \psi^{\prime \prime}=q_{w}^{\prime} \wedge \neg\left((M, w) \otimes_{P^{\prime}} \psi^{\prime \prime}\right)=q_{\delta}^{\prime} \wedge \neg\left((M, w) \otimes_{P^{\prime}} \psi^{\prime \prime}\right)$ because $q_{w}^{\prime}=\bigvee\left\{p^{\prime} \in P^{\prime} \mid M, w \models \operatorname{Pre}\left(p^{\prime}\right)\right\}=\bigvee\left\{p^{\prime} \in P^{\prime} \mid \delta \rightarrow \operatorname{Pre}\left(p^{\prime}\right) \in \mathrm{K}\right\}$ because $M, w \models \delta$, and for all $p^{\prime} \in P^{\prime} \operatorname{deg}\left(\operatorname{Pre}\left(p^{\prime}\right)\right) \leq \operatorname{deg}(\delta)$. Therefore, $q_{w}^{\prime}=q_{\delta}^{\prime}$. So, $(M, w) \Theta_{P^{\prime}} \neg \psi^{\prime \prime} \leftrightarrow q_{\delta}^{\prime} \wedge \neg\left(\delta Q_{P^{\prime}} \psi^{\prime \prime}\right) \in \mathrm{K}^{\mathrm{P}^{\prime}}$ by Induction Hypothesis. That is, $(M, w) \otimes_{P^{\prime}} \phi^{\prime \prime} \leftrightarrow \delta \otimes_{P^{\prime}} \phi^{\prime \prime} \in \mathrm{K}^{\mathrm{P}^{\prime}}$.

- Case $\phi^{\prime \prime}=B_{j} \psi^{\prime \prime}$ :

$$
(M, w) \otimes_{P^{\prime}} B_{j} \psi^{\prime \prime}=q_{w}^{\prime} \wedge \bigwedge_{v \in R_{j}(w)} B_{j}\left(q_{v}^{\prime} \rightarrow(M, v) \otimes_{P^{\prime}} \psi^{\prime \prime}\right)=q_{\delta}^{\prime} \wedge \bigwedge_{v \in R_{j}(w)} B_{j}\left(q_{v}^{\prime} \rightarrow\right.
$$

$\left.(M, v) \otimes_{P^{\prime}} \psi^{\prime \prime}\right)$. Now, for all $v \in R_{j}(v)$, there is $\delta_{j} \in R_{j}(\delta)$ such that $M, v \models \delta_{j}$, because $M, w \models \delta$. Moreover, $q_{v}^{\prime}=q_{\delta_{j}}^{\prime}$. Then, by Induction Hypothesis,

$$
\bigwedge_{v \in R_{j}(w)} B_{j}\left(q_{v}^{\prime} \rightarrow(M, v) \otimes_{P^{\prime}} \psi^{\prime \prime}\right) \leftrightarrow \bigwedge_{\delta_{j} \in R_{j}(\delta)} B_{j}\left(q_{\delta_{j}}^{\prime} \rightarrow \delta_{j} \otimes_{P^{\prime}} \psi^{\prime \prime}\right) \in \mathrm{K}^{\mathrm{P}^{\prime}}
$$

$$
\begin{aligned}
& \text { So, }(M, w) \vartheta_{P^{\prime}} B_{j} \psi^{\prime \prime} \leftrightarrow q_{\delta}^{\prime} \wedge \bigwedge_{\delta_{j} \in R_{j}(\delta)} B_{j}\left(q_{\delta_{j}}^{\prime} \rightarrow \delta_{j} \vartheta_{P^{\prime}} \psi^{\prime \prime}\right) \in \mathrm{K}^{\mathrm{P}^{\prime}} \text {, i.e. }(M, w) \vartheta_{P^{\prime}} \\
& B_{j} \psi^{\prime \prime} \leftrightarrow \delta \otimes_{P^{\prime}} B_{j} \psi^{\prime \prime} \in \mathrm{K}^{\mathrm{P}^{\prime}} \text {, i.e. }(M, w) \vartheta_{P^{\prime}} \phi^{\prime \prime} \leftrightarrow \delta \otimes_{P^{\prime}} \phi^{\prime \prime} \in \mathrm{K}^{\mathrm{P}^{\prime}} .
\end{aligned}
$$

Proof of Theorem \%. It holds that $M^{\prime}, w^{\prime} \models \phi \otimes_{P^{\prime}} \phi^{\prime \prime}$ iff $M^{\prime}, w^{\prime} \models \bigvee\left\{\delta Q_{P^{\prime}} \phi^{\prime \prime} \mid \delta \in S_{n+N}\right.$ and $\left.\delta \rightarrow \phi \in \mathrm{K}\right\}$, iff $M^{\prime}, w^{\prime}=\delta Q_{P^{\prime}} \phi^{\prime \prime}$ for some $\delta \in S_{n+N}$ such that $\delta \rightarrow \phi \in \mathrm{K}$, 
iff $M^{\prime}, w^{\prime} \models(M, w) Q_{P^{\prime}} \phi^{\prime \prime}$ for some pointed $\mathcal{L}$-model $(M, w)$ such that $M, w \models \delta$, for some $\delta \in S_{n+N}$ such that $\delta \rightarrow \phi \in \mathrm{K}$, by Lemma 1 ,

iff $M^{\prime}, w^{\prime}=(M, w) \oslash \phi^{\prime \prime}$ for some pointed $\mathcal{L}$-model $(M, w)$ such that $M, w=\phi$, iff there is a pointed $\mathcal{L}$-model $(M, w)$ such that $M, w \models \phi, M, w \models \operatorname{Pre}\left(w^{\prime}\right)$ and $(M, w) \otimes$ $\left(M^{\prime}, w^{\prime}\right) \models \phi^{\prime \prime}$ by Theorem 6 .

\subsubsection{Connection between DEL-sequents $\phi,\left.\phi^{\prime \prime}\right|^{2} \phi^{\prime}$ and epistemic planning $\phi Q_{P^{\prime}} \phi^{\prime \prime}$}

Finally, the following central theorem connects DEL-sequents with the notion of epistemic planning.

Theorem 8. Let $\phi, \phi^{\prime \prime} \in \mathcal{L}$ and $\phi^{\prime} \in \mathcal{L}^{\prime}$. Let $P^{\prime}$ be a finite subset of $\Phi^{\prime}$. Then,

$$
\phi, \phi^{\prime \prime} \mid \frac{2}{\kappa^{P^{\prime}}} \phi^{\prime} \text { iff } \phi \otimes_{P^{\prime}} \phi^{\prime \prime} \rightarrow \phi^{\prime} \in K^{P^{\prime}}
$$

Just as for the case of progression, Theorem 8 shows that the notion of epistemic planning from $\phi$ to $\phi^{\prime \prime}$ is an analogue in a dynamic setting of the notion of prime implicate in propositional logic. Indeed, Theorem 8 states that $\phi Q_{P^{\prime}} \phi^{\prime \prime}$ captures all the information which can be inferred about the event that occurred, when everything we know about the initial situation is that it satisfies $\phi$, and everything we know about the final situation is that it satifies $\phi^{\prime \prime}$. The counterpart of Theorem 8 for the dual operator $\phi[\theta]_{P^{\prime}} \phi^{\prime \prime}$ states the following:

$$
\phi, \phi^{\prime} \bigvee_{\mathrm{K}^{\mathrm{P}}} \phi^{\prime \prime} \text { iff } \phi^{\prime} \rightarrow \phi[\theta]_{P^{\prime}} \phi^{\prime \prime} \in \mathrm{K}^{\mathrm{P}^{\prime}} .
$$

To prove Theorem 8, we first prove the following lemma.

Lemma 2. Let $\phi, \phi^{\prime \prime} \in \mathcal{L}$, let $\phi^{\prime} \in \mathcal{L}^{\prime}$ and let $P^{\prime}$ be a finite subset of $\Phi^{\prime}$. Then, $\phi \otimes_{P^{\prime}} \phi^{\prime \prime} \rightarrow$ $\phi^{\prime} \in K^{P^{\prime}}$ if and only if for all pointed $\mathcal{L}$-model $(M, w)$ such that $M, w=\phi$, it holds that $(M, w) \vartheta_{P^{\prime}} \phi^{\prime \prime} \rightarrow \phi^{\prime} \in K^{P^{\prime}}$.

Proof. Let $\phi, \phi^{\prime \prime} \in \mathcal{L}$ and $\phi^{\prime} \in \mathcal{L}^{\prime}$. Let $P^{\prime}$ be a finite subset of $\Phi^{\prime}$. Let $n=\operatorname{deg}\left(\phi^{\prime \prime}\right)$ and $N=\max \left\{\operatorname{deg}\left(\operatorname{Pre}\left(p^{\prime}\right)\right) \mid p^{\prime} \in P^{\prime}\right\}$. Then,

$\phi \ominus_{P^{\prime}} \phi^{\prime \prime} \rightarrow \phi^{\prime} \in \mathrm{K}^{\mathrm{P}^{\prime}}$

iff $\bigvee\left\{\delta \theta_{P^{\prime}} \phi^{\prime \prime} \mid \delta \in S_{n+N}, \delta \rightarrow \phi \in \mathrm{K}\right\} \rightarrow \phi^{\prime} \in \mathrm{K}^{\mathrm{P}^{\prime}}$ by definition of $\phi Q_{P^{\prime}} \phi^{\prime \prime}$

iff for all $\delta \in S_{n+N}$ such that $\delta \rightarrow \phi \in \mathrm{K}$, it holds that $\delta \otimes_{P^{\prime}} \phi^{\prime \prime} \rightarrow \phi^{\prime} \in \mathrm{K}^{\mathrm{P}^{\prime}}$

iff for all pointed $\mathcal{L}$-model $(M, w)$ such that $M, w \models \phi$, it holds that $(M, w) Q_{P^{\prime}} \phi^{\prime \prime} \rightarrow$ $\phi^{\prime} \in \mathrm{K}^{\mathrm{P}^{\prime}}$ by Proposition 2 .

Now, we prove Theorem 8:

Proof of Theorem 8. It holds that $\phi, \phi^{\prime \prime} \frac{2}{\mathrm{~K}^{\mathrm{P}^{\mathrm{P}}}} \phi^{\prime}$

iff for all pointed $\mathcal{L}$-model $(M, w)$ and $\mathcal{L}^{\prime}$-model $\left(M^{\prime}, w^{\prime}\right)$ such that $M, w=\operatorname{Pre}\left(w^{\prime}\right)$, if $M, w \models \phi$ and $(M, w) \otimes\left(M^{\prime}, w^{\prime}\right)=\phi^{\prime \prime}$, then $M^{\prime}, w^{\prime}=\phi^{\prime}$,

iff for all pointed $\mathcal{L}$-model $(M, w)$ such that $M, w \models \phi$, for all pointed $\mathcal{L}^{\prime}$-model $\left(M^{\prime}, w^{\prime}\right)$,

if $M, w \models \operatorname{Pre}\left(w^{\prime}\right)$ and $(M, w) \otimes\left(M^{\prime}, w^{\prime}\right) \models \phi^{\prime \prime}$, then $M^{\prime}, w^{\prime} \models \phi^{\prime}$,

iff for all pointed $\mathcal{L}$-model $(M, w)$ such that $M, w \models \phi$, for all pointed $\mathcal{L}^{\prime}$-model $\left(M^{\prime}, w^{\prime}\right)$, if $M^{\prime}, w^{\prime}=(M, w) \otimes_{P^{\prime}} \phi^{\prime \prime}$, then $M^{\prime}, w^{\prime}=\phi^{\prime}$,

iff for all pointed $\mathcal{L}$-model $(M, w)$ such that $M, w=\phi$, for all pointed $\mathcal{L}^{\prime}$-model $\left(M^{\prime}, w^{\prime}\right)$,

$M^{\prime}, w^{\prime}=(M, w) \otimes_{P^{\prime}} \phi^{\prime \prime} \rightarrow \phi^{\prime}$,

iff for all pointed $\mathcal{L}$-model $(M, w)$ such that $M, w \models \phi,(M, w) \otimes_{P^{\prime}} \phi^{\prime \prime} \rightarrow \phi^{\prime} \in \mathrm{K}^{\mathrm{P}^{\prime}}$, iff $\phi Q_{P^{\prime}} \phi^{\prime \prime} \rightarrow \phi^{\prime} \in \mathrm{K}^{\mathrm{P}^{\prime}}$ by Lemma 2 . 


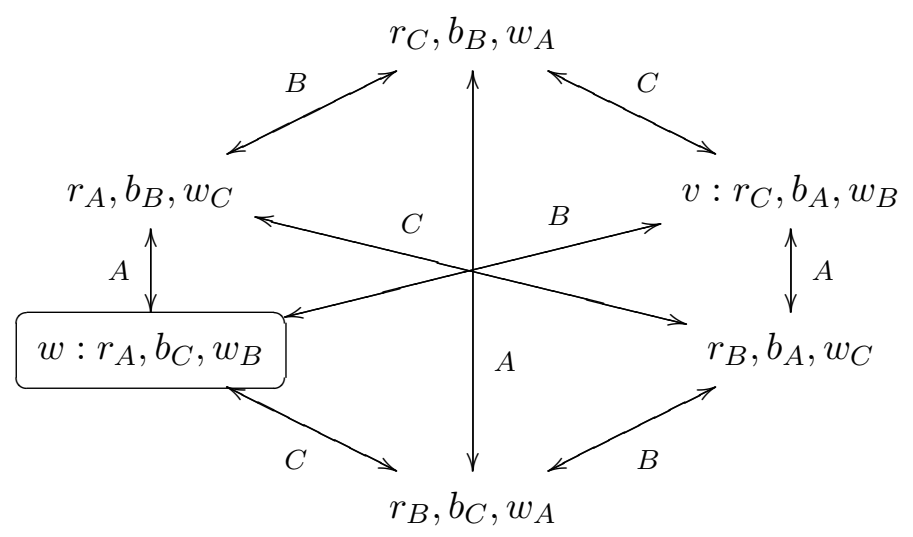

Figure 1. Cards Example

Finally, note that Theorems 6,7 and 8 can easily be generalized similarly to other logics than $\mathrm{K}$ and $\mathrm{K}^{\mathrm{P}^{\prime}}$ in case the class of frames these logics define is stable for the product update.

\subsection{Example}

We take over the Card Example of (Aucher, 2011), that we recall here. Assume that agents A, B and C play a card game with three cards: a white one, a red one and a blue one. Each of them has a single card but they do not know the cards of the other players. At each step of the game, some of the players show their/her/his card to another player or to both other players, either privately or publicly. We want to study and represent the dynamics of the agents' beliefs in this game. The initial situation is represented by the pointed $\mathcal{L}$-model $(M, w)$ of Figure 1 . In this example, $\Phi=\left\{r_{j}, b_{j}, w_{j} \mid j \in\{A, B, C\}\right\}$ where $r_{j}$ stands for 'agent $j$ has the red card', $b_{j}$ stands for 'agent $\mathrm{j}$ has the blue card' and $w_{j}$ stands for 'agent $j$ has the $w$ hite card'. The boxed possible world corresponds to the actual world. The propositional letters not mentioned in the possible worlds do not hold in these possible worlds. The accessibility relations are represented by arrows indexed by agents between possible worlds. Reflexive arrows are omitted in the figure, which means that for all worlds $v \in M$ and all agents $j \in\{A, B, C\}, v \in R_{j}(v)$.

In the situation depicted in this $\mathcal{L}$-model, agent $\mathrm{B}$ does not know that agent $\mathrm{A}$ has the red card and does not know that agent $\mathrm{C}$ has the blue card: $M, w \models\left(\left\langle B_{B}\right\rangle r_{A} \wedge\right.$ $\left.\left\langle B_{B}\right\rangle \neg r_{A}\right) \wedge\left(\left\langle B_{B}\right\rangle b_{C} \wedge\left\langle B_{B}\right\rangle \neg b_{C}\right)$. Our problem is therefore the following:

What sufficient and necessary property (i.e. 'minimal' property) an event should fulfill so that its occurence in the initial situation $(M, w)$ results in a situation where agent $\mathrm{B}$ knows the true state of the world, i.e. agent $\mathrm{B}$ knows that agent $\mathrm{A}$ has the red card and that agent $\mathrm{C}$ has the blue card?

The answer to this question obviously depends on the kind of atomic events we consider. In this example, the events $P^{\prime}=\left\{p^{\prime}, q^{\prime}, r^{\prime}\right\}$ under consideration are the following. First, agent $\mathrm{C}$ shows her blue card $\left(p^{\prime}\right)$, second, agent A shows her red card $\left(q^{\prime}\right)$, and third, agent $\mathrm{B}$ herself shows her white card $\left(r^{\prime}\right)$. Therefore, the preconditions of these atomic events are the following: $\operatorname{Pre}\left(p^{\prime}\right)=b_{C}, \operatorname{Pre}\left(q^{\prime}\right)=r_{A}$ and $\operatorname{Pre}\left(r^{\prime}\right)=w_{B}$. Answering this question amounts to compute the formula $(M, w) \otimes_{P^{\prime}} B_{B}\left(r_{A} \wedge b_{C} \wedge w_{B}\right)$ :

$$
\begin{aligned}
(M, w) \vartheta_{P^{\prime}} B_{B}\left(r_{A} \wedge b_{C} \wedge w_{B}\right)= & q_{w}^{\prime} \wedge B_{B}\left(q_{w}^{\prime} \rightarrow(M, w) \vartheta_{P^{\prime}} r_{A}\right) \wedge \\
& B_{B}\left(q_{v}^{\prime} \rightarrow(M, v) \vartheta_{P^{\prime}} r_{A}\right) \\
= & q_{w}^{\prime} \wedge B_{B}\left(q_{w}^{\prime} \rightarrow q_{w}^{\prime}\right) \wedge B_{B}\left(q_{v}^{\prime} \rightarrow \perp\right)
\end{aligned}
$$


This last formula can be simplified. Indeed,

$$
\begin{aligned}
\left(q_{w}^{\prime} \wedge B_{B}\left(q_{w}^{\prime} \rightarrow q_{w}^{\prime}\right) \wedge B_{B}\left(q_{v}^{\prime} \rightarrow \perp\right)\right) & \leftrightarrow\left(q_{w}^{\prime} \wedge B_{B} \neg q_{v}^{\prime}\right) \in \mathrm{K}^{\mathrm{P}^{\prime}}, \\
\left(q_{w}^{\prime} \wedge B_{B} \neg q_{v}^{\prime}\right) & \leftrightarrow\left(\left(p^{\prime} \vee q^{\prime} \vee r^{\prime}\right) \wedge B_{B} \neg r^{\prime}\right) \in \mathrm{K}^{\mathrm{P}^{\prime}}, \\
\left(\left(p^{\prime} \vee q^{\prime} \vee r^{\prime}\right) \wedge B_{B} \neg r^{\prime}\right) & \leftrightarrow B_{B}\left(p^{\prime} \vee q^{\prime}\right) \in \mathrm{K}^{\mathrm{P}^{\prime}} .
\end{aligned}
$$

So, finally,

$$
(M, w) \otimes_{P^{\prime}} B_{B}\left(r_{A} \wedge b_{C} \wedge w_{B}\right) \leftrightarrow B_{B}\left(p^{\prime} \vee q^{\prime}\right) \in \mathrm{K}^{\mathrm{P}^{\prime}}
$$

In other words, this result states that agent $\mathrm{B}$ should believe either that agent $\mathrm{A}$ shows her red card or that agent $\mathrm{C}$ shows her blue card in order to know the true state of the world. Indeed, since there are only three different cards which are known by the agents and agent B already knows her card, if she learns the card of (at least) one of the other agents, she will also be able to infer the card of the third agent.

\section{Regression}

In this section, we address Question 3 of the introduction. We start in Section 5.1 by addressing Question 3)a). We first deal with epistemic events (Section 5.1.1), then ontic events (Section 5.1.2), and we eventually generalize our results to other logics than $\mathrm{K}$ (Section 5.1.3). Then, in Section 5.2, we address Question 3)b). Finally, in Section 5.3, we provide an example of regression.

\subsection{Definition and axiomatization of $\phi^{\prime}, \phi^{\prime \prime} \stackrel{3}{=} \phi$}

Definition 16 (Inference relation $\phi^{\prime}, \phi^{\prime \prime} \stackrel{3}{=}^{=}$). Let $\phi, \phi^{\prime \prime} \in \mathcal{L}$ and $\phi^{\prime} \in \mathcal{L}^{\prime}$. The inference relation $\phi^{\prime}, \phi^{\prime \prime} \stackrel{3}{=} \phi$ is defined as follows:

$\phi^{\prime}, \phi^{\prime \prime} \stackrel{3}{=} \phi \quad$ iff $\quad$ for all pointed $\mathcal{L}^{\prime}$-model $\left(M^{\prime}, w^{\prime}\right)$, and $\mathcal{L}$-model $\left(M^{\prime \prime}, w^{\prime \prime}\right)$ such that $M^{\prime}, w^{\prime}=\phi^{\prime}$ and $M^{\prime \prime}, w^{\prime \prime} \models \phi^{\prime \prime}$, for all pointed $\mathcal{L}$-model $(M, w)$ such that $M, w \models \operatorname{Pre}\left(w^{\prime}\right)$ and $(M, w) \otimes\left(M^{\prime}, w^{\prime}\right)$ is bisimilar to $\left(M^{\prime \prime}, w^{\prime \prime}\right)$, it holds that $M, w \models \phi$

Just as for $\phi, \phi^{\prime \prime} \models^{2} \phi^{\prime}$, the following proposition states that $\phi, \phi^{\prime} \models \phi^{\prime \prime}$ and $\phi^{\prime}, \phi^{\prime \prime} \models^{3} \phi$ are in fact interdefinable. Besides, this proposition also shows that the somehow complex definition of $\phi^{\prime}, \phi^{\prime \prime} \stackrel{3}{\models}^{\prime} \phi$ can be simplified into a more compact definition.

Proposition 4. Let $\phi, \phi^{\prime \prime} \in \mathcal{L}$ and $\phi^{\prime} \in \mathcal{L}^{\prime}$.

$$
\begin{aligned}
& \phi^{\prime}, \phi^{\prime \prime} \stackrel{3}{=} \phi \quad \text { iff } \neg \phi, \phi^{\prime} \models \neg \phi^{\prime \prime} \\
& \phi^{\prime}, \phi^{\prime \prime} \stackrel{3}{=} \phi \quad \text { iff } \quad \text { for all pointed } \mathcal{L} \text {-model }(M, w) \text {, and } \mathcal{L}^{\prime} \text {-model }\left(M^{\prime}, w^{\prime}\right) \text { such that } \\
& M, w \models \operatorname{Pre}\left(w^{\prime}\right) \text {, if } M^{\prime}, w^{\prime} \models \phi^{\prime} \text { and }(M, w) \otimes\left(M^{\prime}, w^{\prime}\right) \models \phi^{\prime \prime} \text { then } \\
& M, w \models \phi
\end{aligned}
$$

Proof. The proof is similar to the proof of Proposition 3.

\subsubsection{The case of epistemic events}

We provide two equivalent sequent calculi which axiomatize the inference relation $\phi^{\prime}, \phi^{\prime \prime} \stackrel{3}{=} \phi$. As explained in the proof of Theorem 9, Proposition 3 allows us to easily transfer the results obtained for Question 1)a) in (Aucher, 2011) to answer Question 3)a). 
Definition 17 (DEL-Sequent Calculus $\mathrm{SC}^{3}$ ). The DEL-Sequent Calculus $\mathrm{SC}^{3}$ is defined by the following axiom schemata and inference rules. Below, $\perp$ (resp. $\top$ ) stands for any $\mathrm{K}$-inconsistent formula (resp. K-theorem), and $\perp^{\prime}$ (resp. $\mathrm{T}^{\prime}$ ) stands for any $\mathrm{K}^{\prime}$ inconsistent formula (resp. $\mathrm{K}^{\prime}$-theorem).

$$
\begin{aligned}
& \phi^{\prime},\left.\phi^{\prime \prime}\right|^{-} \top \quad \mathrm{A}_{1} \quad \perp^{\prime},\left.\phi^{\prime \prime}\right|^{3} \phi \quad \mathrm{A}_{2} \quad \phi^{\prime},\left.\perp\right|^{3} \phi \quad \mathrm{A}_{3} \\
& \top^{\prime},\left.p\right|^{3} p \quad \mathrm{~A}_{4} \quad \top^{\prime},\left.\neg p\right|^{3} \neg p \quad \mathrm{~A}_{5} \quad p^{\prime},\left.\top\right|^{3} \operatorname{Pre}\left(p^{\prime}\right) \quad \mathrm{A}_{6} \\
& \frac{\phi^{\prime},\left.\neg \phi^{\prime \prime}\right|^{3} \phi \quad \phi^{\prime},\left.\phi^{\prime \prime} \wedge \psi^{\prime \prime}\right|^{3} \phi}{\phi^{\prime},\left.\psi^{\prime \prime}\right|^{3} \phi} \mathrm{R}_{1} \frac{\phi^{\prime},\left.\phi^{\prime \prime}\right|^{3} \psi \rightarrow \phi \quad \phi^{\prime},\left.\phi^{\prime \prime}\right|^{3} \psi}{\phi^{\prime},\left.\phi^{\prime \prime}\right|^{3} \phi} \mathrm{R}_{2} \\
& \frac{\phi^{\prime} \wedge \psi^{\prime},\left.\phi^{\prime \prime}\right|^{3} \phi \quad \neg \psi^{\prime},\left.\phi^{\prime \prime}\right|^{-} \phi}{\phi^{\prime},\left.\phi^{\prime \prime}\right|^{-3} \phi} \mathrm{R}_{3} \frac{\phi^{\prime},\left.\phi^{\prime \prime}\right|^{3} \phi}{B_{j} \phi^{\prime},\left.\left\langle B_{j}\right\rangle \phi^{\prime \prime}\right|^{3}\left\langle B_{j}\right\rangle \phi} \mathrm{R}_{4} \\
& \frac{\phi^{\prime}, \phi^{\prime \prime} \stackrel{3}{-}^{\prime} \phi}{\left\langle B_{j}\right\rangle\left(\phi^{\prime} \wedge p^{\prime}\right),\left.B_{j} \phi^{\prime \prime}\right|^{-} B_{j}\left(\operatorname{Pre}\left(p^{\prime}\right) \rightarrow \phi\right)} \mathrm{R}_{5}
\end{aligned}
$$

Definition 18 (DEL-Sequent Calculus $\mathrm{SC}^{3^{*}}$ ). The DEL-Sequent Calculus $\mathrm{SC}^{3^{*}}$ is defined by the following axiom schemata and inference rules, together with the axiom schemata $A_{2}$ and $A_{6}$ and inference rules $R_{4}$ and $R_{5}$ of the DEL-Sequent Calculus $S^{3}$. Below, $\phi_{p}$ stands for any propositional formula.

$$
\begin{aligned}
& \top^{\prime},\left.\phi_{p}\right|^{3^{*}} \phi_{p} \quad \mathrm{~A}_{7} \quad \frac{\phi^{\prime},\left.\phi^{\prime \prime}\right|^{3^{*}} \phi \quad \phi^{\prime},\left.\psi^{\prime \prime}\right|^{3^{*}} \phi}{\phi^{\prime},\left.\phi^{\prime \prime} \vee \psi^{\prime \prime}\right|^{3^{*}} \phi} \mathrm{R}_{6} \\
& \frac{\phi^{\prime},\left.\phi^{\prime \prime}\right|^{3^{*}} \phi \quad \psi^{\prime},\left.\phi^{\prime \prime}\right|^{3^{*}} \phi}{\phi^{\prime} \vee \psi^{\prime},\left.\phi^{\prime \prime}\right|^{3^{*}} \phi} \mathrm{R}_{7} \frac{\phi^{\prime},\left.\phi^{\prime \prime}\right|^{3^{*}} \phi \quad \phi^{\prime},\left.\phi^{\prime \prime}\right|^{3^{*}} \psi}{\phi^{\prime},\left.\phi^{\prime \prime}\right|^{3^{*}} \phi \wedge \psi} \mathrm{R}_{8} \\
& \frac{\phi^{\prime},\left.\phi^{\prime \prime}\right|^{3^{*}} \phi}{\phi^{\prime},\left.\psi^{\prime \prime}\right|^{3^{*}} \psi} \mathrm{R}_{9} \quad \frac{\phi^{\prime},\left.\phi^{\prime \prime}\right|^{3^{*}} \phi}{\psi^{\prime},\left.\phi^{\prime \prime}\right|^{3^{*}} \phi} \mathrm{R}_{10}
\end{aligned}
$$

where $\phi \rightarrow \psi, \psi^{\prime \prime} \rightarrow \phi^{\prime \prime} \in \mathrm{K} \quad$ where $\psi^{\prime} \rightarrow \phi^{\prime} \in \mathrm{K}^{\prime}$.

Theorem 9 (Soundness and completeness of $\mathrm{SC}^{3}$ and $\mathrm{SC}^{3^{*}}$ ). Let $\phi, \phi^{\prime \prime} \in \mathcal{L}$ and $\phi^{\prime} \in \mathcal{L}^{\prime}$. It holds that $\phi^{\prime}, \phi^{\prime \prime} \stackrel{3}{=}^{\prime} \phi$ if and only if $\phi^{\prime},\left.\phi^{\prime \prime}\right|^{-3} \phi$. It also holds that $\phi^{\prime}, \phi^{\prime \prime} \stackrel{3}{=} \phi$ if and only if $\phi^{\prime},\left.\phi^{\prime \prime}\right|^{3^{*}} \phi$.

Proof. The proof is similar to the proof of Theorem 3. It follows from Proposition 4 and the soundness and completeness of the DEL-Sequent calculus SC of (Aucher, 2011).

Theorem 10. (Aucher et al., 2011, 2012) Given some formulas $\phi, \phi^{\prime \prime} \in \mathcal{L}$ and $\phi^{\prime} \in \mathcal{L}^{\prime}$, the problem of determining whether $\phi^{\prime}, \phi^{\prime \prime} \stackrel{3}{=} \phi$ holds is decidable and NEXPTIMEcomplete. 


\subsubsection{The case of ontic events}

Proposition 4 allows us to easily transfer previous results to the case of ontic events as well, like for the case of $\phi,\left.\phi^{\prime \prime}\right|^{2} \phi^{\prime}$. If in the definition of the product update, the definition of the new valuation given by Equation 4 is replaced by Equation 12, then the inference relation $\phi, \phi^{\prime \prime} \stackrel{2}{=}^{\prime} \phi^{\prime}$ in the case of ontic events is axiomatized by the same sequent calculus $\mathrm{SC}^{3^{*}}$ except that the axiom schemas $\mathrm{A}_{4}$ and $\mathrm{A}_{5}$ are replaced by the following two Axiom schemas:

$$
\begin{array}{ll}
\mathrm{A}_{4}^{\prime} & p^{\prime},\left.p\right|^{3} \operatorname{Sub}\left(p^{\prime}\right)(p) \\
\mathrm{A}_{5}^{\prime} & p^{\prime},\left.\neg p\right|^{3} \neg \operatorname{Sub}\left(p^{\prime}\right)(p)
\end{array}
$$

\subsubsection{Extension to other logics}

Just as in Section 4, all the results of this section can be extended to other logics than $\mathrm{K}$ and $\mathrm{K}^{\prime}$ in case the class of frames defined by these logics is stable for the product update.

Let $\mathcal{C}$ be a class of $\mathcal{L}$-models and let $\mathcal{C}^{\prime}$ be a class of $\mathcal{L}^{\prime}$-models. The inference relation $\phi^{\prime \prime}, \phi^{\prime} \frac{3}{\frac{\mathcal{C}, \mathcal{C}^{\prime}}{}} \phi$ is defined as follows:

$$
\begin{aligned}
\phi^{\prime}, \phi^{\prime \prime} \frac{3}{\overline{c, \mathcal{C}^{\prime}}} \phi \quad \text { iff } & \text { for all pointed } \mathcal{L} \text {-model }(M, w) \text { of } \mathcal{C}, \text { and } \mathcal{L}^{\prime} \text {-model }\left(M^{\prime}, w^{\prime}\right) \text { of } \mathcal{C}^{\prime} \\
& \text { such that } M, w \models \operatorname{Pre}\left(w^{\prime}\right), \text { if } M^{\prime}, w^{\prime} \models \phi^{\prime} \text { and }(M, w) \otimes\left(M^{\prime}, w^{\prime}\right) \models \\
& \phi^{\prime \prime} \text { then } M, w \models \phi .
\end{aligned}
$$

Let $\mathrm{L}$ be a logic. The DEL-sequent calculus $S C_{L, L^{\prime}}^{3}$ is defined as the DEL-sequent calculus $\mathrm{SC}^{3}$, except that the logic $\mathrm{K}$ and $\mathrm{K}^{\prime}$ are replaced by the logic $\mathrm{L}$ and $\mathrm{L}^{\prime}$ respectively.

Theorem 11. Let $L$ be a logic sound and complete for $\mathcal{L}$ with respect to a class $\mathcal{C}$ of $\mathcal{L}$-models and let $L^{\prime}$ be a logic sound and complete for $\mathcal{L}^{\prime}$ with respect to a class $\mathcal{C}^{\prime}$ of $\mathcal{L}^{\prime}$-models. If $\mathcal{C}$ is stable for the product update with respect to $\mathcal{C}^{\prime}$, then for all $\phi, \phi^{\prime \prime} \in \mathcal{L}$ and all $\phi^{\prime} \in \mathcal{L}^{\prime}$, it holds that $\phi^{\prime}, \phi^{\prime \prime} \frac{3}{\overline{\mathcal{C}, \mathcal{C}^{\prime}}} \phi$ if and only if $\phi^{\prime},\left.\phi^{\prime \prime}\right|_{L, L^{\prime}} \phi$.

\subsection{Regression of $\phi^{\prime \prime}$ by $\left(M^{\prime}, w^{\prime}\right)$ and regression of $\phi^{\prime \prime}$ by $\phi^{\prime}$}

Just as for the axiomatizations of $\phi, \phi^{\prime} \vdash \phi^{\prime \prime}$ and $\phi,\left.\phi^{\prime \prime}\right|^{2} \phi^{\prime}$, the axiomatization of $\phi^{\prime},\left.\phi^{\prime \prime}\right|^{3} \phi$ provides us with a means to compute all the necessary properties $\phi$ that held intially, once an event satisfying $\phi^{\prime}$ has occurred and has resulted in a situation where $\phi^{\prime \prime}$ holds. However, we could wonder if there is a more compact way to represent all these properties $\phi$. This is what we will show in this section by introducing the notion of regression of $\phi^{\prime \prime}$ by $\phi^{\prime}: \phi^{\prime} \oslash \phi^{\prime \prime}$.

We build the regression operator $\phi^{\prime} \oslash \phi^{\prime \prime}$ step by step. We start by defining a regression operator $\left(M^{\prime}, w^{\prime}\right) \oslash \phi^{\prime \prime}$ between a pointed $\mathcal{L}^{\prime}$-model $\left(M^{\prime}, w^{\prime}\right)$ and a formula $\phi^{\prime \prime} \in \mathcal{L}$. Then, we extrapolate this definition and define the epistemic planning operator $\delta^{\prime} \oslash \phi^{\prime \prime}$ between a Kit Fine formula $\delta^{\prime}$ and a formula $\phi^{\prime \prime} \in \mathcal{L}$, the formula $\delta^{\prime}$ somehow representing a pointed $\mathcal{L}^{\prime}$-model $\left(M^{\prime}, w^{\prime}\right)$. Finally, we extend this definition to define the full operator $\phi^{\prime} \oslash \phi^{\prime \prime}$, relying on the fact that any formula $\phi^{\prime} \in \mathcal{L}^{\prime}$ can be decomposed equivalently into a disjunction of Kit Fine formulas $\delta^{\prime} \mathrm{s}$.

\subsubsection{Regression of $\phi^{\prime \prime}$ by $\left(M^{\prime}, w^{\prime}\right)$}

Definition 19 (Regression of $\phi^{\prime \prime}$ by $\left(M^{\prime}, w^{\prime}\right)$ ). Let $\left(M^{\prime}, w^{\prime}\right)$ be a pointed $\mathcal{L}^{\prime}$-model and let $\phi^{\prime \prime} \in \mathcal{L}$. The regression of $\phi^{\prime \prime}$ by $\left(M^{\prime}, w^{\prime}\right)$, which we write $\left(M^{\prime}, w^{\prime}\right) \oslash \phi^{\prime \prime}$, is the formula of $\mathcal{L}$ defined as follows: 


$$
\begin{aligned}
\left(M^{\prime}, w^{\prime}\right) \oslash p & =\operatorname{Pre}\left(w^{\prime}\right) \wedge p \\
\left(M^{\prime}, w^{\prime}\right) \oslash\left(\phi^{\prime \prime} \vee \psi^{\prime \prime}\right) & =\left(\left(M^{\prime}, w^{\prime}\right) \oslash \phi^{\prime \prime}\right) \vee\left(\left(M^{\prime}, w^{\prime}\right) \oslash \psi^{\prime \prime}\right) \\
\left(M^{\prime}, w^{\prime}\right) \oslash \neg \phi^{\prime \prime} & =\operatorname{Pre}\left(w^{\prime}\right) \wedge \neg\left(\left(M^{\prime}, w^{\prime}\right) \oslash \phi^{\prime \prime}\right) \\
\left(M^{\prime}, w^{\prime}\right) \oslash\left\langle B_{j}\right\rangle \phi^{\prime \prime} & =\operatorname{Pre}\left(w^{\prime}\right) \wedge \bigvee_{v^{\prime} \in R_{j}\left(w^{\prime}\right)}\left\langle B_{j}\right\rangle\left(\left(M^{\prime}, v^{\prime}\right) \oslash \phi^{\prime \prime}\right)
\end{aligned}
$$

Readers familiar with the BMS formalism (Baltag \& Moss, 2004) might have recognized in Equations 22 the usual reduction axioms. Indeed, if $\left(M^{\prime}, w^{\prime}\right) \oslash \phi$ is replaced by $\left\langle M^{\prime}, w^{\prime}\right\rangle \phi$, we get these reduction axioms back:

$$
\begin{aligned}
& \left\langle M^{\prime}, w^{\prime}\right\rangle p \quad \leftrightarrow \quad \operatorname{Pre}\left(w^{\prime}\right) \wedge p \\
& \left\langle M^{\prime}, w^{\prime}\right\rangle\left(\phi^{\prime \prime} \vee \psi^{\prime \prime}\right) \quad \leftrightarrow \quad\left\langle M^{\prime}, w^{\prime}\right\rangle \phi^{\prime \prime} \vee\left\langle M^{\prime}, w^{\prime}\right\rangle \psi^{\prime \prime} \\
& \left\langle M^{\prime}, w^{\prime}\right\rangle \neg \phi^{\prime \prime} \quad \leftrightarrow \quad \operatorname{Pre}\left(w^{\prime}\right) \wedge \neg\left\langle M^{\prime}, w^{\prime}\right\rangle \phi^{\prime \prime} \\
& \left\langle M^{\prime}, w^{\prime}\right\rangle\left\langle B_{j}\right\rangle \phi^{\prime \prime} \leftrightarrow \operatorname{Pre}\left(w^{\prime}\right) \wedge \bigvee_{v^{\prime} \in R_{j}\left(w^{\prime}\right)}\left\langle B_{j}\right\rangle\left\langle M^{\prime}, v^{\prime}\right\rangle \phi^{\prime \prime} .
\end{aligned}
$$

Theorem 12 below is therefore not surprising, since it corresponds to the truth conditions of the operator $\left\langle M^{\prime}, w^{\prime}\right\rangle \phi$ of the BMS language. This theorem provides an alternative and non-constructive definition of $\left(M^{\prime}, w^{\prime}\right) \oslash \phi^{\prime \prime}$.

Theorem 12. Let $\left(M^{\prime}, w^{\prime}\right)$ be a pointed $\mathcal{L}^{\prime}$-models and let $\phi^{\prime \prime} \in \mathcal{L}$. Then, for all pointed $\mathcal{L}$-model $(M, w)$, it holds that

$$
M, w \models\left(M^{\prime}, w^{\prime}\right) \oslash \phi^{\prime \prime} \quad \text { iff } \quad M, w \models \operatorname{Pre}\left(w^{\prime}\right) \text { and }(M, w) \otimes\left(M^{\prime}, w^{\prime}\right) \models \phi^{\prime \prime}
$$

Definition 24 of Theorem 12 states that, given an event model $\left(M^{\prime}, w^{\prime}\right)$, any initial situation satisfying the formula $\left(M^{\prime}, w^{\prime}\right) \oslash \phi^{\prime \prime}$ will result in a final situation where $\phi^{\prime \prime}$ holds after the occurrence of the event represented by $\left(M^{\prime}, w^{\prime}\right)$. This condition $\left(M^{\prime}, w^{\prime}\right) \oslash \phi^{\prime \prime}$ is not only sufficient but also necessary: any initial situation which does not satisfy the formula $\left(M^{\prime}, w^{\prime}\right) \oslash \phi^{\prime \prime}$ will not result in a final situation where $\phi^{\prime \prime}$ holds after the occurrence of the event represented by $\left(M^{\prime}, w^{\prime}\right)$.

Proof. We prove Theorem 12 by induction on $\phi^{\prime \prime}$.

- Case $\phi^{\prime \prime}=p$ :

First, we prove the implication from left to right. Assume that $M, w \models\left(M^{\prime}, w^{\prime}\right) \oslash$ $p$. Then, by definition, $M, w \models \operatorname{Pre}\left(w^{\prime}\right) \wedge p$. Therefore, $M, w \models \operatorname{Pre}\left(w^{\prime}\right)$ and $M, w \models p$. Hence, by definition of the product update (Equation 4), it also holds that $(M, w) \otimes\left(M^{\prime}, w^{\prime}\right) \models \phi^{\prime \prime}$.

Second, we prove the implication from right to left. Assume that $M, w \models$ $\operatorname{Pre}\left(w^{\prime}\right)$ and $(M, w) \otimes\left(M^{\prime}, w^{\prime}\right)=p$. Then, by definition of the product update, $M, w=p$. Therefore, $M, w \models \operatorname{Pre}\left(w^{\prime}\right) \wedge p$, i.e. $M, w=\left(M^{\prime}, w^{\prime}\right) \oslash p$.

- Case $\phi^{\prime \prime}=\neg \psi^{\prime \prime}$ :

First, we prove the implication from left to right. Assume that $M, w \models\left(M^{\prime}, w^{\prime}\right) \oslash$ $\neg \psi^{\prime \prime}$, i.e. $M, w \models \operatorname{Pre}\left(w^{\prime}\right) \wedge \neg\left(\left(M^{\prime}, w^{\prime}\right) \oslash \psi^{\prime \prime}\right)$. Then, $M, w \models \operatorname{Pre}\left(w^{\prime}\right)$ and $M, w \not \models$ $\left(M^{\prime}, w^{\prime}\right) \oslash \psi^{\prime \prime}$. Therefore, by Induction Hypothesis, $M, w \not \models \operatorname{Pre}\left(w^{\prime}\right)$ or $(M, w) \otimes$ $\left(M^{\prime}, w^{\prime}\right) \not \models \psi^{\prime \prime}$. Now, because $M, w \models \operatorname{Pre}\left(w^{\prime}\right)$, it holds that $(M, w) \otimes\left(M^{\prime}, w^{\prime}\right) \models$ $\neg \psi^{\prime \prime}$, i.e. $(M, w) \otimes\left(M^{\prime}, w^{\prime}\right) \models \phi^{\prime \prime}$. So, finally, $M, w \models \operatorname{Pre}\left(w^{\prime}\right)$ and $(M, w) \otimes$ $\left(M^{\prime}, w^{\prime}\right) \models \phi^{\prime \prime}$.

Second, we prove the implication from right to left. Assume that $M, w \models$ $\operatorname{Pre}\left(w^{\prime}\right)$ and $(M, w) \otimes\left(M^{\prime}, w^{\prime}\right)=\phi^{\prime \prime}$. Then, $(M, w) \otimes\left(M^{\prime}, w^{\prime}\right) \not \models \psi^{\prime \prime}$, so by Induc- 
tion Hypothesis, $M, w \not \models\left(M^{\prime}, w^{\prime}\right) \oslash \psi^{\prime \prime}$. Hence, $M, w=\operatorname{Pre}\left(w^{\prime}\right) \wedge \neg\left(M^{\prime}, w^{\prime}\right) \oslash \psi^{\prime \prime}$, i.e. $M, w \models\left(M^{\prime}, w^{\prime}\right) \oslash \neg \psi^{\prime \prime}$ by the Equations 22. So, finally, $M, w \models\left(M^{\prime}, w^{\prime}\right) \oslash \phi^{\prime \prime}$.

- Case $\phi^{\prime \prime}=\phi_{1}^{\prime \prime} \vee \phi_{2}^{\prime \prime}$ :

We only prove the implication from left to right, the other direction being proved similarly. Assume that $M, w \models\left(M^{\prime}, w^{\prime}\right) \oslash \phi_{1}^{\prime \prime} \vee \phi_{2}^{\prime \prime}$. Then, by the Equations 22, $M, w \models\left(M^{\prime}, w^{\prime}\right) \oslash \phi_{1}^{\prime \prime}$ or $M, w \models\left(M^{\prime}, w^{\prime}\right) \oslash \phi_{2}^{\prime \prime}$. So, by Induction Hypothesis, $\left(M, w \models \operatorname{Pre}\left(w^{\prime}\right)\right.$ and $\left.(M, w) \otimes\left(M^{\prime}, w^{\prime}\right) \models \phi_{1}^{\prime \prime}\right)$ or $\left(M, w=\operatorname{Pre}\left(w^{\prime}\right)\right.$ and $(M, w) \otimes$ $\left.\left(M^{\prime}, w^{\prime}\right) \models \phi_{2}^{\prime \prime}\right)$. Therefore, $M, w \models \operatorname{Pre}\left(w^{\prime}\right)$ and $\left((M, w) \otimes\left(M^{\prime}, w^{\prime}\right) \models \phi_{1}^{\prime \prime}\right.$ or $\left.(M, w) \otimes\left(M^{\prime}, w^{\prime}\right)=\phi_{2}^{\prime \prime}\right)$. So, finally, $M, w \models \operatorname{Pre}\left(w^{\prime}\right)$ and $(M, w) \otimes\left(M^{\prime}, w^{\prime}\right) \models$ $\phi_{1}^{\prime \prime} \vee \phi_{2}^{\prime \prime}$, i.e. $M, w \models \operatorname{Pre}\left(w^{\prime}\right)$ and $(M, w) \otimes\left(M^{\prime}, w^{\prime}\right) \models \phi^{\prime \prime}$.

- Case $\phi^{\prime \prime}=\left\langle B_{j}\right\rangle \psi^{\prime \prime}$ :

First, we prove the implication from left to right. Assume that $M, w \models$ $\left(M^{\prime}, w^{\prime}\right) \oslash\left\langle B_{j}\right\rangle \psi^{\prime \prime}$. Then, by definition of Equations $22, M, w \models \operatorname{Pre}\left(w^{\prime}\right) \wedge$ $\bigvee\left\langle B_{j}\right\rangle\left(\left(M^{\prime}, v^{\prime}\right) \oslash \psi^{\prime \prime}\right)$. Therefore, $M, w \models \operatorname{Pre}\left(w^{\prime}\right)$ and there is $v^{\prime} \in R_{j}\left(w^{\prime}\right)$ $v^{\prime} \in R_{j}\left(w^{\prime}\right)$

such that $M, w=\left\langle B_{j}\right\rangle\left(\left(M^{\prime}, v^{\prime}\right) \oslash \psi^{\prime \prime}\right)$. Then, by Induction Hypothesis, there is $v \in R_{j}(w)$ such that $M, v \models \operatorname{Pre}\left(v^{\prime}\right)$ and $(M, v) \otimes\left(M^{\prime}, v^{\prime}\right) \models \psi^{\prime \prime}$. Hence, there is $\left(v, v^{\prime}\right) \in R_{j}\left(w, w^{\prime}\right)$ such that $(M, v) \otimes\left(M^{\prime}, v^{\prime}\right) \models \psi^{\prime \prime}$. Therefore, $(M, w) \otimes\left(M^{\prime}, w^{\prime}\right) \models$ $\left\langle B_{j}\right\rangle \psi^{\prime \prime}$.

Second, we prove the implication from right to left. Assume that $M, w \models$ $\operatorname{Pre}\left(w^{\prime}\right)$ and $(M, w) \otimes\left(M^{\prime}, w^{\prime}\right) \models\left\langle B_{j}\right\rangle \psi^{\prime \prime}$. Then, there is $\left(v, v^{\prime}\right) \in R_{j}\left(w, w^{\prime}\right)$ such that $(M, v) \otimes\left(M^{\prime}, v^{\prime}\right) \models \psi^{\prime \prime}$. Then, $M, v \models \operatorname{Pre}\left(v^{\prime}\right)$ and $(M, v) \otimes\left(M^{\prime}, v^{\prime}\right) \models$ $\psi^{\prime \prime}$. Therefore, by Induction Hypothesis, $M, v \models\left(M^{\prime}, v^{\prime}\right) \oslash \psi^{\prime \prime}$. Now, because $v \in R_{j}(w)$, it holds that $M, w \models\left\langle B_{j}\right\rangle\left(\left(M^{\prime}, v^{\prime}\right) \oslash \psi^{\prime \prime}\right)$. Therefore, $M, w \models$

$\bigvee_{v^{\prime} \in R_{j}\left(w^{\prime}\right)}\left\langle B_{j}\right\rangle\left(\left(M^{\prime}, v^{\prime}\right) \oslash \psi^{\prime \prime}\right)$. So, finally, $M, w \models \operatorname{Pre}\left(w^{\prime}\right) \wedge \bigvee_{v^{\prime} \in R_{j}\left(w^{\prime}\right)}\left\langle B_{j}\right\rangle\left(\left(M^{\prime}, v^{\prime}\right) \oslash\right.$ $\left.\psi^{\prime \prime}\right)$ i.e. $M, w=\left(M^{\prime}, w^{\prime}\right) \oslash\left\langle B_{j}\right\rangle \psi^{\prime \prime}$. That is $M, w \models\left(M^{\prime}, w^{\prime}\right) \oslash \phi^{\prime \prime}$.

\subsubsection{Regression of $\phi^{\prime \prime}$ by $\phi^{\prime}$}

We can generalize the notion of regression of $\phi^{\prime \prime}$ by $\left(M^{\prime}, w^{\prime}\right)$ by considering that the event is incompletely described by a formula $\phi^{\prime}$. This leads us to define the notion of regression of $\phi^{\prime \prime}$ by $\phi^{\prime}$.

Definition 20 (Regression of $\phi^{\prime \prime}$ by $\phi^{\prime}$ ). Let $\phi^{\prime \prime} \in \mathcal{L}, \phi^{\prime} \in \mathcal{L}^{\prime}$, and let $n=$ $\max \left\{\operatorname{deg}\left(\phi^{\prime \prime}\right), \operatorname{deg}\left(\phi^{\prime}\right)\right\}$. Let $P^{\prime}$ be the set of propositional letters appearing in $\phi^{\prime}$. Then, by Corollary 2, there is a subset $S^{\prime} \subseteq S_{n}^{P^{\prime}}$ such that $\phi^{\prime} \leftrightarrow \bigvee_{\delta^{\prime} \in S^{\prime}} \delta^{\prime} \in \mathrm{K}^{\prime}$. The regression of $\phi^{\prime \prime}$ by $\phi^{\prime}$, which we write $\phi^{\prime} \oslash \phi^{\prime \prime}$, is defined as follows:

$$
\phi^{\prime} \oslash \phi^{\prime \prime}=\bigvee\left\{\delta^{\prime} \oslash \phi^{\prime \prime} \mid \delta^{\prime} \in S^{\prime}\right\}
$$

where $\delta^{\prime} \oslash \phi^{\prime \prime}$ is defined inductively as follows:

$$
\begin{aligned}
\delta^{\prime} \oslash p & =\operatorname{Pre}\left(\delta^{\prime}\right) \wedge p \\
\delta^{\prime} \oslash\left(\phi^{\prime \prime} \vee \psi^{\prime \prime}\right) & =\left(\delta^{\prime} \oslash \phi^{\prime \prime}\right) \vee\left(\delta^{\prime} \oslash \psi^{\prime \prime}\right) \\
\delta^{\prime} \oslash \neg \phi^{\prime \prime} & =\operatorname{Pre}\left(\delta^{\prime}\right) \wedge \neg\left(\delta^{\prime} \oslash \phi^{\prime \prime}\right) \\
\delta^{\prime} \oslash\left\langle B_{j}\right\rangle \phi^{\prime \prime} & =\operatorname{Pre}\left(\delta^{\prime}\right) \wedge \bigvee_{\gamma^{\prime} \in R_{j}\left(\delta^{\prime}\right)}\left\langle B_{j}\right\rangle\left(\gamma^{\prime} \oslash \phi^{\prime \prime}\right)
\end{aligned}
$$

The following theorem provides an alternative and non-constructive definition of the operator $\phi^{\prime} \oslash \phi^{\prime \prime}$. 
Theorem 13. Let $\phi^{\prime} \in \mathcal{L}^{\prime}$ and $\phi^{\prime \prime} \in \mathcal{L}$, and let $P^{\prime}$ be a finite subset of $\Phi^{\prime}$. Then, for all $\mathcal{L}$-model $(M, w)$, it holds that

$$
M, w \models \phi^{\prime} \oslash \phi^{\prime \prime} \quad \text { iff } \quad \begin{aligned}
& \text { there is }\left(M^{\prime}, w^{\prime}\right) \text { such that } M^{\prime}, w^{\prime} \models \phi^{\prime}, \\
& M, w \models \operatorname{Pre}\left(w^{\prime}\right) \text { and }(M, w) \otimes\left(M^{\prime}, w^{\prime}\right) \models \phi^{\prime \prime}
\end{aligned}
$$

Note that we could define a dual operator of $\phi^{\prime} \oslash \phi^{\prime \prime}$ as follows:

$$
\phi^{\prime}[\oslash] \phi^{\prime \prime}=\neg\left(\phi^{\prime} \oslash \neg \phi^{\prime \prime}\right)
$$

Then, the counterpart of Theorem 13 for this dual operator is as follows:

$$
\begin{array}{ll}
M, w \models \phi^{\prime}[\oslash] \phi^{\prime \prime} \quad \text { iff } \quad \text { for all }\left(M^{\prime}, w^{\prime}\right) \text { such that } M^{\prime}, w^{\prime} \models \phi^{\prime} \\
\quad \text { if } M, w \models \operatorname{Pre}\left(w^{\prime}\right) \text { then }(M, w) \otimes\left(M^{\prime}, w^{\prime}\right) \models \phi^{\prime \prime}
\end{array}
$$

This definition entails that, given any initial situation satisfying $\phi^{\prime}[\oslash] \phi^{\prime \prime}$, any event satisfying $\phi^{\prime}$ occurring in this situation would result in a final situation where $\phi^{\prime \prime}$ holds true:

$$
\phi^{\prime}[\oslash] \phi^{\prime \prime}, \phi^{\prime} \leftarrow \phi^{\prime \prime}
$$

To prove Theorem 13, we rely on Lemma 3 below, whose proof is very similar to the proof of Lemma 1 (so we do not repeat it here). The proof of Theorem 13 then follows the same lines as the proof of Theorem 8 .

Lemma 3. Let $\phi^{\prime \prime} \in \mathcal{L}$, let $P^{\prime}$ be a finite subset of $\Phi^{\prime}$, and let $n=\operatorname{deg}\left(\phi^{\prime \prime}\right)$. Then, for all pointed $\mathcal{L}^{\prime}$-model $\left(M^{\prime}, w^{\prime}\right)$, for all $\delta^{\prime} \in S_{n}^{P^{\prime}}$ such that $M^{\prime}, w^{\prime} \models \delta^{\prime}$, it holds that $\left(M^{\prime}, w^{\prime}\right) \oslash \phi^{\prime \prime} \leftrightarrow \delta^{\prime} \oslash \phi^{\prime \prime} \in K$

\subsubsection{Connection between DEL-sequents $\phi^{\prime},\left.\phi^{\prime \prime}\right|^{3} \phi$ and regression $\phi^{\prime} \oslash \phi^{\prime \prime}$}

Finally, the following central theorem connects DEL-sequents with the notion of regression.

Theorem 14. Let $\phi, \phi^{\prime \prime} \in \mathcal{L}$ and let $\phi^{\prime} \in \mathcal{L}^{\prime}$. Then,

$$
\phi^{\prime},\left.\phi^{\prime \prime}\right|^{3} \phi \text { iff } \phi^{\prime} \oslash \phi^{\prime \prime} \rightarrow \phi \in K
$$

Just as for progression and epistemic planning, this theorem shows that the notion of regression of $\phi^{\prime \prime}$ by $\phi^{\prime}$ is an analogue in a dynamic setting of the notion of prime implicate in propositional logic. Indeed, Theorem 14 states that $\phi^{\prime} \oslash \phi^{\prime \prime}$ captures all the information which can be inferred about the initial situation, when everything we know about the event that just occured is that it satisfies $\phi^{\prime}$, and everything we know about the final situation is that it satifies $\phi^{\prime \prime}$. The counterpart of Theorem 14 for the dual operator $\phi^{\prime}[\oslash] \phi^{\prime \prime}$ states the following:

$$
\phi, \phi^{\prime} \vdash \phi^{\prime \prime} \text { iff } \phi \rightarrow \phi^{\prime}[\oslash] \phi^{\prime \prime} \in \mathrm{K} .
$$

To prove Theorem 14, we will rely on the following lemma whose proof is similar to the proof of Lemma 2.

Lemma 4. Let $\phi, \phi^{\prime \prime} \in \mathcal{L}$, and let $\phi^{\prime} \in \mathcal{L}^{\prime}$. Then, $\phi^{\prime} \oslash \phi^{\prime \prime} \rightarrow \phi \in K$ if and only if for all pointed $\mathcal{L}^{\prime}$-model $\left(M^{\prime}, w^{\prime}\right)$ such that $M^{\prime}, w^{\prime} \models \phi^{\prime},\left(M^{\prime}, w^{\prime}\right) \otimes_{P^{\prime}} \phi^{\prime \prime} \rightarrow \phi \in K$.

We can now prove Theorem 14: 


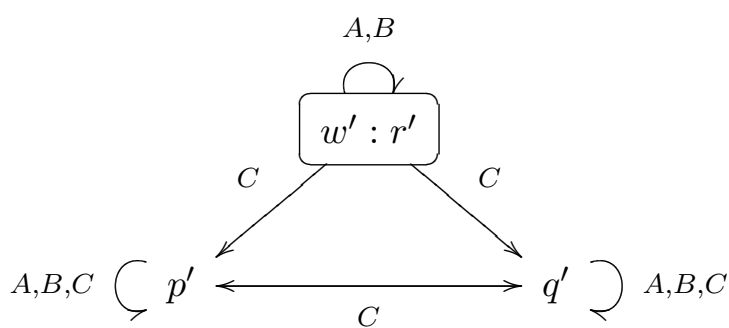

Figure 2. Players A and B show their cards to each other in front of player C

Proof. It holds that $\phi^{\prime},\left.\phi^{\prime \prime}\right|^{3} \phi$

iff for all pointed $\mathcal{L}$-model $(M, w)$ and $\mathcal{L}^{\prime}$-model $\left(M^{\prime}, w^{\prime}\right)$ such that $M, w \models \operatorname{Pre}\left(w^{\prime}\right)$, if $M^{\prime}, w^{\prime}=\phi^{\prime}$ and $(M, w) \otimes\left(M^{\prime}, w^{\prime}\right) \models \phi^{\prime \prime}$, then $M, w \models \phi$,

iff for all pointed $\mathcal{L}^{\prime}$-model $\left(M^{\prime}, w^{\prime}\right)$ such that $M^{\prime}, w^{\prime} \models \phi^{\prime}$, for all pointed $\mathcal{L}$-model $(M, w)$, if $M, w \models \operatorname{Pre}\left(w^{\prime}\right)$ and $(M, w) \otimes\left(M^{\prime}, w^{\prime}\right) \models \phi^{\prime \prime}$, then $M, w \models \phi$,

iff for all pointed $\mathcal{L}^{\prime}$-model $\left(M^{\prime}, w^{\prime}\right)$ such that $M^{\prime}, w^{\prime} \models \phi^{\prime}$, for all pointed $\mathcal{L}$-model $(M, w)$, if $M, w \models\left(M^{\prime}, w^{\prime}\right) \oslash \phi^{\prime \prime}$, then $M, w \models \phi$, by Theorem 12

iff for all pointed $\mathcal{L}^{\prime}$-model $\left(M^{\prime}, w^{\prime}\right)$ such that $M^{\prime}, w^{\prime} \models \phi^{\prime}$, for all pointed $\mathcal{L}$-model $(M, w)$, it holds that $M, w=\left(M^{\prime}, w^{\prime}\right) \oslash \phi^{\prime \prime} \rightarrow \phi$,

iff for all pointed $\mathcal{L}^{\prime}$-model $\left(M^{\prime}, w^{\prime}\right)$ such that $M^{\prime}, w^{\prime} \models \phi^{\prime}$, it holds that $\left(M^{\prime}, w^{\prime}\right) \oslash \phi^{\prime \prime} \rightarrow$ $\phi \in \mathrm{K}$,

iff $\phi^{\prime} \oslash \phi^{\prime \prime} \rightarrow \phi \in \mathrm{K}$ by Lemma 4 .

Finally, note that Theorems 12, 13 and 14 can easily be generalized similarly to other logics than $\mathrm{K}$ and $\mathrm{K}^{\prime}$ in case the class of frames these logics define is stable for the product update.

\subsection{Example}

Let us resume our Card Example and assume that players A and B show their card to each other. As it turns out, C noticed that A showed her card to B but did not notice that $\mathrm{B}$ did so to A. Players A and B know this. This event is represented by the $\mathcal{L}^{\prime}$-model $\left(M^{\prime}, w^{\prime}\right)$ of Figure 2. The boxed possible event $w^{\prime}$ corresponds to the actual event. The atomic event $p^{\prime}$ stands for 'player A shows her red card', $q^{\prime}$ stands for the atomic event 'player A shows her $w$ hite card' and $r^{\prime}$ stands for the atomic event 'players A and B show their red and white cards respectively to each other'. The precondition $\operatorname{Pre}\left(p^{\prime}\right)$ of $p^{\prime}$ is $r_{A}$, the precondition $\operatorname{Pre}\left(q^{\prime}\right)$ of $q^{\prime}$ is $w_{A}$, and the precondition $\operatorname{Pre}\left(r^{\prime}\right)$ of $r^{\prime}$ is $r_{A} \wedge w_{B}$. As a result of this event, the agents update their beliefs. In the resulting model, the following holds for example: $(M, w) \otimes\left(M^{\prime}, w^{\prime}\right)=B_{B}\left(r_{A} \wedge w_{B} \wedge b_{C}\right)$. It states that player A 'knows' the true state of the world. Therefore, it holds that $M, w=\left(M^{\prime}, w^{\prime}\right) \oslash B_{B}\left(r_{A} \wedge w_{B} \wedge b_{C}\right)$. But this resulting knowledge of agent $B$ might be due to the specific intial epistemic state of agent B. So, our problem is the following:

What sufficient and necessary property (i.e. 'minimal' property) an initial situation should fulfill so that the occurrence of the event represented by $\left(M^{\prime}, w^{\prime}\right)$ results in a situation where agent $\mathrm{B}$ knows the true state of the world, i.e. agent $\mathrm{B}$ knows that agent $\mathrm{A}$ has the red card and that agent $\mathrm{C}$ has the blue card?

Answering this question boils down to compute the formula $\left(M^{\prime}, w^{\prime}\right) \oslash B_{B}\left(r_{A} \wedge w_{B} \wedge b_{C}\right)$ :

$$
\begin{aligned}
& \left(M^{\prime}, w^{\prime}\right) \oslash B_{B}\left(r_{A} \wedge w_{B} \wedge b_{C}\right) \\
& =\left(M^{\prime}, w^{\prime}\right) \oslash \neg\left\langle B_{B}\right\rangle\left(\neg r_{A} \vee \neg w_{B} \vee \neg b_{C}\right) \\
& =\operatorname{Pre}\left(w^{\prime}\right) \wedge \neg\left(M^{\prime}, w^{\prime}\right) \oslash\left\langle B_{B}\right\rangle\left(\neg r_{A} \vee \neg w_{B} \vee \neg b_{C}\right)
\end{aligned}
$$




$$
\begin{aligned}
= & r_{A} \wedge w_{B} \wedge \neg\left\langle B_{B}\right\rangle\left(M^{\prime}, w^{\prime}\right) \oslash\left(\neg r_{A} \vee \neg w_{B} \vee \neg b_{C}\right) \\
= & r_{A} \wedge w_{B} \wedge \neg\left\langle B_{B}\right\rangle\left(\left(M^{\prime}, w^{\prime}\right) \oslash \neg r_{A} \vee\left(M^{\prime}, w^{\prime}\right) \oslash \neg w_{B} \vee\left(M^{\prime}, w^{\prime}\right) \oslash \neg b_{C}\right) \\
= & r_{A} \wedge w_{B} \wedge \neg\left\langle B_{B}\right\rangle\left(\left(\left(r_{A} \wedge w_{B}\right) \wedge \neg\left(M^{\prime}, w^{\prime}\right) \oslash r_{A}\right) \vee\left(\left(r_{A} \wedge w_{B}\right) \wedge \neg\left(M^{\prime}, w^{\prime}\right) \oslash w_{B}\right) \vee\right. \\
& \left.\left(\left(r_{A} \wedge w_{B}\right) \wedge \neg\left(M^{\prime}, w^{\prime}\right) \oslash b_{C}\right)\right) \\
= & r_{A} \wedge w_{B} \wedge \neg\left\langle B_{B}\right\rangle\left(\left(r_{A} \wedge w_{B} \wedge \neg r_{A}\right) \vee\left(r_{A} \wedge w_{B} \wedge b_{C}\right) \vee\left(r_{A} \wedge w_{B} \wedge \neg b_{C}\right)\right)
\end{aligned}
$$

Now, $r_{A} \wedge w_{B} \wedge \neg\left\langle B_{B}\right\rangle\left(\left(r_{A} \wedge w_{B} \wedge \neg r_{A}\right) \vee\left(r_{A} \wedge w_{B} \wedge b_{C}\right) \vee\left(r_{A} \wedge w_{B} \wedge \neg b_{C}\right)\right) \leftrightarrow r_{A} \wedge$ $w_{B} \wedge B_{B}\left(\neg\left(r_{A} \wedge w_{B}\right) \vee b_{C}\right) \in \mathrm{K}$. So, finally,

$$
\left(M^{\prime}, w^{\prime}\right) \oslash B_{B}\left(r_{A} \wedge w_{B} \wedge b_{C}\right) \leftrightarrow\left(r_{A} \wedge w_{B}\right) \wedge B_{B}\left(r_{A} \wedge w_{B} \rightarrow b_{C}\right) \in \mathrm{K}
$$

This formula states that the necessary and sufficient condition that an initial situation should fulfill so that the occurrence of the event represented by $\left(M^{\prime}, w^{\prime}\right)$ in this situation results in a final situation where agent B 'knows' the true state of the world is that agent A does have the red card, agent $\mathrm{B}$ does have the white card and that agent $\mathrm{B}$ believes that, under these assumptions, agent $\mathrm{C}$ has the blue card.

\section{Generalizing BMS}

In this section, we show how the BMS language introduced by Baltag, $M$ oss and $S$ olecki in (Baltag \& Moss, 2004; Batlag et al., 1998) can be generalized to account for incomplete descriptions of events.

\subsection{The BMS language}

The standard BMS language is defined by resorting to the notion of action signature, which is closely related to the notion of $\mathcal{L}^{\prime}$-model. An action signature is a tuple $\Sigma=$ $\left(W^{\prime}, R^{\prime},\left(w_{1}^{\prime}, \ldots, w_{n}^{\prime}\right)\right)$ where: 1$) W^{\prime}$ is a non-empty and finite set of action types (possible events are called "action types" in the BMS formalism), 2) $R^{\prime}: A g t \rightarrow 2^{W^{\prime} \times W^{\prime}}$ is a function assigning to each agent $j \in A g t$ an accessibility relation on $W^{\prime}$, and 3) $\left\{w_{1}^{\prime}, \ldots, w_{n}^{\prime}\right\}$ is a subset of $W^{\prime}$ such that for all $i, j \in\{1, \ldots, n\}$, if $i \neq j$ then $w_{i}^{\prime} \neq w_{j}^{\prime}$.

If we consider an action signature $\Sigma=\left(W^{\prime}, R^{\prime},\left(w_{1}^{\prime}, \ldots, w_{n}^{\prime}\right)\right)$ together with a set of formulas $\phi_{1}, \ldots, \phi_{n} \in \mathcal{L}$, then we can get back an $\mathcal{L}^{\prime}$-model. The $\mathcal{L}^{\prime}$-model associated to $\left(\Sigma, \phi_{1}, \ldots, \phi_{n}\right)$ is the tuple $M^{\prime}=\left(W^{\prime}, R^{\prime}, V^{\prime}\right)$ where the valuation $V^{\prime}$ is defined as follows. We pick $q^{\prime} \in \Phi^{\prime}$ such that $\operatorname{Pre}\left(q^{\prime}\right)=\top$, and for all $i \in\{1, \ldots, n\}$, we pick $p_{i}^{\prime} \in \Phi^{\prime}$ such that $\operatorname{Pre}\left(p_{i}^{\prime}\right)=\phi_{i}$. Then, for all $i \in\{1, \ldots, n\}$ we set $V^{\prime}\left(p_{i}^{\prime}\right)=\left\{w_{i}^{\prime}\right\}$, we also set $V^{\prime}\left(q^{\prime}\right)=W^{\prime}-\left\{w_{1}^{\prime}, \ldots, w_{n}^{\prime}\right\}$, and for all $p^{\prime} \in \Phi^{\prime}-\left\{q^{\prime}, p_{1}^{\prime}, \ldots, p_{n}^{\prime}\right\}$ we set $V^{\prime}\left(p^{\prime}\right)=\emptyset$. Note that a $\mathcal{L}^{\prime}$-model associated to $\left(\Sigma, \phi_{1}, \ldots, \phi_{n}\right)$ is a complete $\mathcal{L}^{\prime}$-model.

Definition 21 (BMS Language). Let $\Sigma=\left(W^{\prime}, R^{\prime},\left(w_{1}^{\prime}, \ldots, w_{n}^{\prime}\right)\right)$ be an action signature. The BMS language $\mathcal{L}_{\Sigma}$ is defined inductively as follows.

$$
\mathcal{L}_{\Sigma}: \phi \quad:=p \quad|\neg \phi \quad| \quad \phi \wedge \phi \quad\left|\quad B_{j} \phi \quad\right| \quad\left[\Sigma, w^{\prime}, \phi_{1}, \ldots, \phi_{n}\right] \phi
$$

where $p$ ranges over $\Phi$ and $\phi_{1}, \ldots, \phi_{n}$ range over $\mathcal{L}$.

Let $(M, w)$ be a pointed $\mathcal{L}$-model. The truth conditions for the language $\mathcal{L}_{\Sigma}$ are defined as in Definition 2, except for the operator $\left[\Sigma, w^{\prime}, \phi_{1}, \ldots, \phi_{n}\right] \phi$ :

$$
M, w=\left[\Sigma, w^{\prime}, \phi_{1}, \ldots, \phi_{n}\right] \phi \quad \text { iff } \quad M, w \models \operatorname{Pre}\left(w^{\prime}\right) \text { implies }(M, w) \otimes\left(M^{\prime}, w^{\prime}\right) \models \phi
$$

where $\left(M^{\prime}, w^{\prime}\right)$ is the $\mathcal{L}^{\prime}$-model associated to $\Sigma$ and $\phi_{1}, \ldots, \phi_{n}$. 
The intuitive reading of the modality $\left[\Sigma, w^{\prime}, \phi_{1}, \ldots, \phi_{n}\right] \phi$ is " $\phi$ holds after the occurrence of an event, whose perception by the agents is completely represented by the $\mathcal{L}^{\prime}$-model associated to $\Sigma$ and $\phi_{1}, \ldots, \phi_{n} "$.

\subsection{A generalization of the BMS language}

With the BMS language $\mathcal{L}_{\Sigma}$ that we just spelled out, one can reason about the effects of events only when these events are fully specified and described by means of event models. This is obviously a limitation since agents are often confronted to situations where they only have a partial perception of the events happening: some agents may simply be out of their sight for instance. Therefore, we introduce the dynamic modality $\left[\phi^{\prime}\right] \phi$, whose intuitive reading is " $\phi$ holds after the occurrence of any event satisfying $\phi^{\prime \prime}$ ", or in other words " $\phi$ holds after the occurence of an event such that what we only know about this event is that it satisfies $\phi^{\prime \prime}$. The formula $\phi^{\prime}$ typically describes partially and incompletely the event occurring, although it could provide a full description of it as well.

Definition 22 (Language $\mathcal{L}_{F}$ ). The language $\mathcal{L}_{F}$ is defined inductively as follows:

$$
\mathcal{L}_{F}: \phi \quad:=p|\neg \phi| \phi \wedge \phi\left|B_{j} \phi\right| \quad\left[\phi^{\prime}\right] \phi
$$

where $p$ ranges over $\Phi, \phi^{\prime}$ ranges over $\mathcal{L}^{\prime}$ and $j$ over Agt. The formula $\left\langle\phi^{\prime}\right\rangle \phi$ is an abbreviation of the formula $\neg\left[\phi^{\prime}\right] \neg \phi$.

Let $(M, w)$ be a pointed $\mathcal{L}$-model. The truth conditions for the language $\mathcal{L}_{F}$ are defined as in Definition 2, except for the operator $\left[\phi^{\prime}\right] \phi$ :

$$
M, w \models\left[\phi^{\prime}\right] \phi \quad \text { iff } \quad \begin{aligned}
& \text { for all pointed } \mathcal{L}^{\prime} \text {-model }\left(M^{\prime}, w^{\prime}\right) \text { such that } M^{\prime}, w^{\prime} \models \phi^{\prime}, \\
& \text { if } M, w \models \operatorname{Pre}\left(w^{\prime}\right) \text { then }(M, w) \otimes\left(M^{\prime}, w^{\prime}\right) \models \phi^{\prime \prime}
\end{aligned}
$$

Note that the definition of $\left[\phi^{\prime}\right] \phi$ is identical to the definition of $\phi^{\prime}[\oslash] \phi$ in Equation 28.

To show that the BMS language can be embedded in the language $\mathcal{L}_{F}$, we define the translation $t: \mathcal{L}_{\Sigma} \rightarrow \mathcal{L}_{F}$ inductively as follows:

$$
\begin{aligned}
t(p) & =p \\
t(\neg \phi) & =\neg t(\phi) \\
t(\phi \wedge \psi) & =t(\phi) \wedge t(\psi) \\
t\left(B_{j} \phi\right) & =B_{j} t(\phi) \\
t\left(\left[\Sigma, w^{\prime}, \phi_{1}, \ldots, \phi_{n}\right] \phi\right) & =\left[\delta_{k}\left(M^{\prime}, w^{\prime}\right)\right] t(\phi)
\end{aligned}
$$

where $k=\operatorname{deg}(\phi)$ and $\left(M^{\prime}, w^{\prime}\right)$ is the pointed (and complete) $\mathcal{L}^{\prime}$-model associated to $\left(\Sigma, w^{\prime}, \phi_{1}, \ldots, \phi_{n}\right)$.

Theorem 15. Let $(M, w)$ be a pointed epistemic model and let $\phi \in \mathcal{L}_{\Sigma}$. It holds that $M, w=\phi$ if and only if $M, w=t(\phi)$.

Proof. The proof is by induction on the formula $\phi$. The only non trivial case is when $\phi$ is of the form $B_{j} \psi$. This case is proved by the fact that for all $k \in \mathbb{N}$, for all pointed, complete and finite $\mathcal{L}^{\prime}$-model $\left(M^{\prime}, w^{\prime}\right)$, the formula $\delta_{k}\left(M^{\prime}, w^{\prime}\right) \in \mathcal{L}^{\prime}$ is such that 1) $\left.M^{\prime}, w^{\prime} \models \delta_{k}\left(M^{\prime}, w^{\prime}\right), 2\right)$ for all pointed $\mathcal{L}^{\prime}$-model $\left(M^{\prime \prime}, w^{\prime \prime}\right)$, if $M^{\prime \prime}, w^{\prime \prime} \models \delta_{n}\left(M^{\prime}, w^{\prime}\right)$ then $\left(M^{\prime}, w^{\prime}\right)$ and $\left(M^{\prime \prime}, w^{\prime \prime}\right)$ are $k$-bisimilar (see (Blackburn et al., 2001, p. 74) for the definition of $k$-bisimilarity). 
Finally, we provide a sound and complete axiomatization of the language $\mathcal{L}_{F}$ :

Theorem 16. The logic $L_{F}$ defined below is a sound and complete axiomatization of $\mathcal{L}_{F}$ with respect to the class of $\mathcal{L}$-models. Below, the formula $\delta^{\prime}$ stands for any Kit Fine formula for $K^{\prime}$.

$$
\begin{aligned}
& \text { (Epistemic) } \\
& \left(\left[\phi^{\prime}\right] \text {-distribution }\right) \\
& \left(\left[\phi^{\prime}\right] \text {-necessitation }\right)
\end{aligned}
$$

(Event Consistency)

(Atomic Permanence)

(Partial Functionality)

(Action Knowledge)

(Decomposition)

(Transfer)

\section{Basic axioms and rules}

All axiom schemes and inference rules of $\mathrm{K}$

$\vdash\left[\phi^{\prime}\right](\phi \rightarrow \psi) \rightarrow\left(\left[\phi^{\prime}\right] \phi \rightarrow\left[\phi^{\prime}\right] \psi\right)$

If $\vdash \phi$ then $\vdash\left[\phi^{\prime}\right] \phi$

\section{Event axioms}

$$
\vdash[\perp] \phi
$$

$\vdash\left[\delta^{\prime}\right] p \leftrightarrow\left(\operatorname{Pre}\left(\delta^{\prime}\right) \rightarrow p\right)$

$\vdash\left[\delta^{\prime}\right] \neg \phi \leftrightarrow\left(\operatorname{Pre}\left(\delta^{\prime}\right) \rightarrow \neg\left[\delta^{\prime}\right] \phi\right)$

if $\operatorname{deg}\left(\delta^{\prime}\right) \geq \operatorname{deg}(\phi)$

$\vdash\left[\delta^{\prime}\right] B_{j} \phi \leftrightarrow\left(\operatorname{Pre}\left(\delta^{\prime}\right) \rightarrow \bigwedge_{\gamma^{\prime} \in R_{j}\left(\delta^{\prime}\right)} B_{j}\left[\gamma^{\prime}\right] \phi\right)$

if $\operatorname{deg}\left(\delta^{\prime}\right)>\operatorname{deg}(\phi)$

$\vdash\left\langle\phi^{\prime} \vee \psi^{\prime}\right\rangle \phi \leftrightarrow\left\langle\phi^{\prime}\right\rangle \phi \vee\left\langle\psi^{\prime}\right\rangle \phi$

\section{Bridge Rule}

If $\vdash^{\prime} \phi^{\prime} \rightarrow \psi^{\prime}$ then $\vdash\left\langle\phi^{\prime}\right\rangle \phi \rightarrow\left\langle\psi^{\prime}\right\rangle \phi$

Proof. The proof of soundness is routine. We only prove the completeness of $L_{F}$. Because of Corollary 2, the Transfer rule and the Decomposition axiom, any formula of $\mathcal{L}_{F}$ is provably equivalent to a formula where all the subformulas with dynamic operators are of the form $[\perp] \phi$ or $\left[\delta^{\prime}\right] \phi$, where $\operatorname{deg}\left(\delta^{\prime}\right) \geq \operatorname{deg}(\phi)$. Now, because of the reduction axioms Event Consistency, Atomic Permanence, Partial Functionality and Action Knowledge, one can prove by induction on these subformulas with dynamic operators that they are themselves provably equivalent to epistemic formulae of $\mathcal{L}$. Then, using $\left[\phi^{\prime}\right]$-distribution and $\left[\phi^{\prime}\right]$-necessitation, one proves in general that any formula of $\mathcal{L}_{F}$ is provably equivalent to a formula of $\mathcal{L}$. That is, for all $\phi \in \mathcal{L}_{F}$, there is $\psi \in \mathcal{L}$ such that $\phi \leftrightarrow \psi \in \mathrm{L}_{\mathrm{F}}$ and therefore also $\models \phi \leftrightarrow \psi$, by soundness. Then, if $\models \phi$, then $\models \psi$, so $\psi \in \mathrm{K}$ by completeness of $\mathrm{K}$. Hence, because $\mathrm{K} \subseteq \mathrm{L}_{\mathrm{F}}, \psi \in \mathrm{L}_{\mathrm{F}}$. So, finally, because $\psi \leftrightarrow \phi \in \mathrm{L}_{\mathrm{F}}$, it holds that $\phi \in \mathrm{L}_{\mathrm{F}}$. So, we have proved completeness.

Note that the reduction axioms Atomic Permanence, Partial Functionality and Action Knowledge are the dual of the axioms spelled out in Equation 26 which are themselves an extrapolation of the standard reduction axioms of DEL spelled out in Equation 23. Below are two key theorems of the logic $L_{F}$ :

$$
B_{j}\left[\phi^{\prime}\right] \phi \leftrightarrow\left[B_{j} \phi^{\prime}\right] B_{j} \phi \in \mathrm{L}_{\mathrm{F}}
$$

(Reduction Axiom)

The above theorem of $\mathrm{L}_{\mathrm{F}}$ states that agent $j$ believes now that $\phi$ will hold after the occurrence of any event satisfying $\phi^{\prime}$ iff she will believe that $\phi$ holds after the occurrence of any event during which she believes that $\phi^{\prime}$ holds.

$$
\text { for all } i \neq j, \quad\left[\phi^{\prime} \wedge B_{i} \psi^{\prime}\right] B_{j} \phi \leftrightarrow\left[\phi^{\prime}\right] B_{j} \phi \in \mathrm{L}_{\mathrm{F}} \quad \text { (Independence of Agents) }
$$

The above theorem of $L_{F}$ states that the beliefs of other agents about the event occurring do not affect our own beliefs about the resulting situation. Finally, we have 
the following fact which connects our generalized language $\mathcal{L}_{F}$ with DEL-sequents:

$$
\phi, \phi^{\prime} \vdash \phi^{\prime \prime} \text { iff } \phi \rightarrow\left[\phi^{\prime}\right] \phi^{\prime \prime} \in \mathrm{L}_{\mathrm{F}}
$$

Note that Equation 32 is a rewritting of Equation 31.

\section{Conclusion}

\section{$7.1 \quad$ Related work}

In dynamic epistemic logic, regression and epistemic planning issues have drawn uneven attention.

\subsubsection{Regression}

The regression technique is used very often in the DEL literature. It corresponds to the classical reduction method employed to prove completeness of an axiomatization: a formula with dynamic operator(s) is 'reduced' equivalently to a formula without dynamic operator by pushing the dynamic operator through the logical connectives, performing some kind of regression of the initial formula with dynamic operator.

\subsubsection{Epistemic planning}

Few works address the problem of epistemic planning in DEL. The only works in that direction that we are aware of are rather recent and were developped independently from our work.

In (van der Hoek \& Wooldridge, 2002), van der Hoek and Wooldridge transpose the epistemic planning problem into a problem of model checking in Alternating Temporal Epistemic Logic (ATEL). However, they assume that their semantic structures used to represent the planning domain (called Alternating Epistemic Transition System) is already given and finite.

In (Agotnes \& van Ditmarsch, 2011), Agotnes and van Ditmarsch study what they call "public announcement games", which are games whose actions are simultaneous public announcements by each agent of formulas known by them and whose payoff depends on whether or not a goal epistemic formula is satisfied after the simultaneous public anouncements for each agent. The authors state properties satisfied by these games and connect them with Bayesian games.

In (Löwe, Pacuit, \& Witzel, 2011), Löwe, Pacuit and Witzel present what they call the "(absolute) DEL planning problem": given a pointed $\mathcal{L}$-model, a formula $\phi \in \mathcal{L}$ and a finite set of $\mathcal{L}^{\prime}$-models, produce a (legal) sequence $\sigma$ of these $\mathcal{L}^{\prime}$-models such that the occurrence of this sequence of events in the initial $\mathcal{L}$-model results in a situation where $\phi$ holds. They show that under very specific conditions (the preconditions of event models are propositional and event models are "almost mutually exclusive"), the DEL planning problem is decidable.

In (Bolander \& Andersen, 2011), Bolander and Andersen prove that the "DEL planning problem" is decidable in case there is a single agent and undecidable in case we deal with ontic events and there are at least three agents (even without the common knowledge modality). They also show that their planning domain generalize some well-known types of planning domains studied in automated planning (Cimatti, Pistore, \& Traverso, 2008; Ghallab, Nau, \& Traverso, 2004). The DEL-planning problem is very close to our epistemic planning problem. An important difference is that we do not deal with a given set of $\mathcal{L}^{\prime}$-models, we instead deal with a given set of atomic events $\Phi^{\prime}$, and that we do not consider sequence of events. This enables us to define decidable procedures which provide the sufficient and necessary condition, under the form of a formula $\phi^{\prime} \in \mathcal{L}^{\prime}$, so 
that the occurrence of an event in the initial situation yields a final situation where $\phi$ holds. One should also note that the undecidability result of (Bolander \& Andersen, 2011) is proved only for ontic events and assuming that there are at least three agents.

\subsection{Concluding remarks}

If we want our formalisms to be applied, our results should be recast into decision procedures leading to implemented reasoning tools. To this aim, we have developped in (Aucher et al., 2011, 2012) a tableau method for our DEL-sequents which has been implemented in LOTRECscheme. Even if this work provides algorithmic methods which address part (a) of the three questions of the introduction, we still need to provide algorithmic methods which address part (b) of these three questions. As pointed out after Definition 15, our recursive definitions of $\phi \otimes \phi^{\prime}, \phi \otimes_{P^{\prime}} \phi^{\prime \prime}$ and $\phi^{\prime} \oslash \phi^{\prime \prime}$ can be seen as algorithmic definitions. Spelling out these algorithms and determining their exact running time complexity is a theoretical prerequisite to determine whether or not our methods are indeed applicable and how they can be applied.

We followed in this paper and its companion paper (Aucher, 2011) the external approach, representing our situations involving several agents from an external and omniscient point of view. However, it would be more appropriate if we want our formalisms to be implemented and used by artificial agents to follow the internal approach (Aucher, 2010) and represent situations from the point of view of the artificial agent itself, as in (Bolander \& Andersen, 2011). Adopting this internal approach might yield quite different definitions and axiomatizations.

\section{Acknowledgements}

The syntax and semantics of the language $\mathcal{L}_{F}$ was defined together with Alexandru Baltag during my visit at Oxford University in May 2010. I thank Hans van Ditmarsch for comments on an earlier version of this paper. I thank the anonymous referees for their helpful comments.

\section{References}

Agotnes, T., \& van Ditmarsch, H. (2011). What will they say?-public announcement games. Synthese, 179, 57-85.

Aucher, G. (2010). An internal version of epistemic logic. Studia Logica, 1, 1-22.

Aucher, G. (2011). DEL-sequents for progression. Journal of Applied Non-Classical Logics, $21(3-4), 289-321$.

Aucher, G., Maubert, B., \& Schwarzentruber, F. (2011). Tableau method and NEXPTIME-completeness of DEL-sequents. Electronic Notes in Theoretical Computer Science, 278, 17-30.

Aucher, G., Maubert, B., \& Schwarzentruber, F. (2012). Generalized DEL-sequents. In L. F. del Cerro, A. Herzig, \& J. Mengin (Eds.), JELIA (Vol. 7519, p. 54-66). Springer.

Baltag, A., \& Moss, L. (2004). Logic for epistemic programs. Synthese, 139(2), 165-224.

Baltag, A., Moss, L., \& Solecki, S. (1999). The logic of public announcements, common knowledge and private suspicions (Tech. Rep.). Indiana University.

Batlag, A., Moss, L. S., \& Solecki, S. (1998). The logic of public announcements and common knowledge and private suspicions. In I. Gilboa (Ed.), TARK (p. 43-56). Morgan Kaufmann. 
Blackburn, P., de Rijke, M., \& Venema, Y. (2001). Modal logic (Vol. 53). Cambridge University Press.

Bolander, T., \& Andersen, M. B. (2011). Epistemic planning for single- and multi-agent systems. Journal of Applied Non-Classical Logics, 21 (1), 9-34.

Cimatti, A., Pistore, M., \& Traverso, P. (2008). Handbook of knowledge representation. In F. van Harmelen, V. Lifschitz, \& B. Porter (Eds.), (chap. Automated Planning). Elsevier.

Ghallab, M., Nau, D., \& Traverso, P. (2004). Automated planning: Theory $\&$ practice. San Francisco: Morgan Kaufmann.

Löwe, B., Pacuit, E., \& Witzel, A. (2011). DEL planning and some tractable cases. In H. P. van Ditmarsch, J. Lang, \& S. Ju (Eds.), LORI (Vol. 6953, p. 179-192). Springer.

Moss, L. S. (2007). Finite models constructed from canonical formulas. Journal of Philosophical Logic, 36(6), 605-640.

van Benthem, J. (2007). Dynamic logic for belief revision. Journal of Applied NonClassical Logics, 17(2), 129-155.

van der Hoek, W., \& Wooldridge, M. (2002). Tractable multiagent planning for epistemic goals. In $A A M A S$ (p. 1167-1174). ACM.

van Ditmarsch, H., van der Hoek, W., \& Kooi, B. (2007). Dynamic epistemic logic (Vol. 337). Springer. 